University of Wollongong

Research Online

Australian Institute for Innovative Materials -

Papers

Australian Institute for Innovative Materials

$1-1-2019$

\title{
Zwitterion Functionalized Silica Nanoparticle Coatings: The Effect of Particle Size on Protein, Bacteria, and Fungal Spore Adhesion
}

\author{
Brianna Knowles \\ University of Wollongong, bs921@uowmail.edu.au \\ Dan Yang \\ University of Wollongong, dy996@uowmail.edu.au \\ Pawel W. Wagner \\ University of Wollongong, pawel@uow.edu.au \\ Shane A. MacLaughlin \\ University of Wollongong, shanemac@uow.edu.au \\ Michael J. Higgins \\ University of Wollongong, mhiggins@uow.edu.au
}

See next page for additional authors

Follow this and additional works at: https://ro.uow.edu.au/aiimpapers

Part of the Engineering Commons, and the Physical Sciences and Mathematics Commons

Research Online is the open access institutional repository for the University of Wollongong. For further information contact the UOW Library: research-pubs@uow.edu.au 


\title{
Zwitterion Functionalized Silica Nanoparticle Coatings: The Effect of Particle Size on Protein, Bacteria, and Fungal Spore Adhesion
}

\author{
Abstract \\ The negative impacts that arise from biologicalfouling of surfaces have driven the development of \\ coatingswith unique physical and chemical properties that are able toprevent interactions with fouling \\ species. Here, we report onlow-fouling hydrophilic coatings presenting nanoscaledfeatures prepared from \\ different size silica nanoparticles(SiNPs) functionalized with zwitterionic chemistries. Zwitter-ionic \\ sulfobetaine siloxane (SB) was reacted to SiNPs rangingin size from 7 to $75 \mathrm{~nm}$. Particle stability and \\ grafting densitywere confirmed using dynamic light scattering and thermog-ravimetric analysis. Thin \\ coatings of nanoparticles were prepared by spin-coating aqueous particle suspensions. The \\ resultingcoatings were characterized using scanning electron microscopy, atomic force microscopy, and \\ contact angle goniometry. SBfunctionalized particle coatings displayed increased hydrophilicity \\ compared to unmodified particle coating controls whileincreasing particle size correlated with increased \\ coating roughness and increased surface area. Coatings of zwitterated particlesdemonstrated a high \\ degree of nonspecific protein resistance, as measured by quartz crystal microgravimetry. Adsorption \\ ofbovine serum albumin and hydrophobin proteins were reduced by up to 91 and $94 \%$, respectively. \\ Adhesion of bacteria(Escherichia coli) to zwitterion modified particle coatings were also significantly \\ reduced over both short and long-term assays. Maximum reductions of $97 \%$ and $94 \%$ were achieved over \\ 2 and $24 \mathrm{~h}$ assay periods, respectively. For unmodified particlecoatings, protein adsorption and bacterial \\ adhesion were generally reduced with increasing particle size. Adhesion of fungalspores to SB modified \\ SiNP coatings was also reduced, however no clear trends in relation to particle size were demonstrated.

\section{Disciplines} \\ Engineering | Physical Sciences and Mathematics

\section{Publication Details} \\ Knowles, B. R., Yang, D., Wagner, P., MacLaughlin, S., Higgins, M. J. \& Molino, P. J. (2019). Zwitterion \\ Functionalized Silica Nanoparticle Coatings: The Effect of Particle Size on Protein, Bacteria, and Fungal \\ Spore Adhesion. Langmuir, 35 (5), 1335-1345.

\section{Authors} \\ Brianna Knowles, Dan Yang, Pawel W. Wagner, Shane A. MacLaughlin, Michael J. Higgins, and Paul J. \\ Molino
}




\title{
Zwitterion Functionalized Silica Nanoparticle
}

\section{Coatings: The Effect of Particle Size on}

\section{Protein, Bacteria, and Fungal Spore Adhesion}

\author{
Brianna R. Knowles, ${ }^{\dagger, \ldots}$ Dan Yang, ${ }^{\dagger, \ddagger}$ Pawel Wagner, \\ Michael J. Higgins, ${ }^{\dagger, \ddagger}$ and Paul J. Molino, ${ }^{*, \ddagger}$ \\ $\dagger A R C$ Industrial Transformation Research Hub for Australian Steel Manufacturing, NSW \\ 2522, Australia \\ $\ddagger$ Intelligent Polymer Research Institute, ARC Centre of Excellence for Electromaterials \\ Science, AIIM Facility, Innovation Campus, University of Wollongong, NSW 2500, \\ Australia \\ 9BlueScope Innovation Laboratories, Old Port Road, Port Kembla, NSW 2505, Australia \\ E-mail: pmolino@uow.edu.au
}

\begin{abstract}
The negative impacts that arise from biological fouling of surfaces have driven the development of coatings with unique physical and chemical properties that are able to prevent interactions with fouling species. Here, we report on low-fouling hydrophilic coatings presenting nanoscaled features prepared from different size silica nanoparticles (SiNPs) functionalized with zwitterionic chemistries. Zwitterionic sulfobetaine siloxane (SB) was reacted to SiNPs ranging in size from 7 to $75 \mathrm{~nm}$. Particle stability and grafting density were confirmed using dynamic light scattering and thermogravimetric analysis. Thin coatings of nanoparticles were prepared by spin-coating aqueous particle suspensions. The resulting coatings were characterized using scanning electron
\end{abstract}


microscopy, atomic force microscopy, and contact angle goniometry. SB functionalized particle coatings displayed increased hydrophilicity compared to unmodified particle coating controls while increasing particle size correlated with increased coating roughness and increased surface area. Coatings of zwitterated particles demonstrated a high degree of nonspecific protein resistance, as measured by quartz crystal microgravimetry (QCM). Adsorption of bovine serum albumin and hydrophobin proteins were reduced by up to 91 and $94 \%$, respectively. Adhesion of bacteria (Escherichia coli) to zwitterion modified particle coatings were also significantly reduced over both short and long-term assays. Maximum reductions of $97 \%$ and $94 \%$ were achieved over 2 and 24 $\mathrm{h}$ assay periods, respectively. For unmodified particle coatings, protein adsorption and bacterial adhesion were generally reduced with increasing particle size. Adhesion of fungal spores to SB modified SiNP coatings was also reduced, however no clear trends in relation to particle size were demonstrated.

\section{Introduction}

Coatings that resist the attachment and build-up of fouling microorganisms are highly sought after across a number of industries. Applications range from prevention of marine biofouling on ship hulls and submerged structures, ${ }^{1,2}$ through to protecting hospital surfaces and medical devices from bacterial contamination in order to reduce the spread of infection and disease. ${ }^{3,4}$ Traditional approaches to prevent fouling have relied on coatings that contain or release biocides such as metal derivatives, ${ }^{5,6}$ poly(ammonium compounds) ${ }^{7-9}$ and antibiotics. ${ }^{10,11}$ Whilst generally effective, these types of coatings often suffer from reduced efficiencies over time, and the release of toxins can have detrimental impacts to non-target organisms and more generally, the environment. ${ }^{12,13}$ Additionally, the overuse of antimicrobial agents has contributed to the emergence of antibiotic-resistant pathogens. ${ }^{14}$

As a result, new strategies for reducing surface fouling have shifted away from incorporation of toxic biocides towards more environmentally benign antifouling coatings, i.e. coatings 
that can minimise and prevent microbial interactions and adhesion. Modulation of surface topography and optimization of coating surface energy are among strategies that have been used to limit microbial adhesion and successfully reduce biological fouling. ${ }^{15,16}$ Low surface energy hydrophobic coatings often present water-repellent and self-cleaning properties, with a minimum bioadhesion achieved when surface energies fall in the range of $20-30 \mathrm{~mJ} / \mathrm{m}^{2}$, as described by Baier. ${ }^{17}$ Furthermore, coating roughness is known to influence the adhesion strength of microorganisms, with topography playing a role in the contactable area available for organisms to adhere. Coatings that present intricate, micro- and nano-scale topographical features of similar size to the fouling species of interest have been shown to limit interactions and reduce binding strength. ${ }^{18-20}$ Whilst coatings with highly structured topographical features have been demonstrated to effectively reduce adhesion of organisms, these coatings are rarely reproducible or robust enough to be produced on a large scale.

In contrast, antifouling coatings developed from hydrophilic (high surface energy) materials provide a non-specific approach for preventing protein and microorganism interactions. Hydrophilic coatings bind water molecules at their interface; forming both a physical and energetic barrier that cannot be penetrated by fouling species. ${ }^{21,22}$ Poly(ethylene glycol) (PEG) has been the most broadly employed hydrophilic polymer for fouling prevention. However, PEG suffers from oxidative degradation in the presence of transition metal ions and is therefore not suited for long term coating applications. ${ }^{23,24}$ Zwitterionic polymers, containing an equal number of positive and negative charges on the same monomer unit, are currently being investigated as a potential substitute for PEG due to their stability and enhanced water binding owing to electrostatically induced hydration. ${ }^{25,26}$ Zwitterion functionalized surfaces have been shown to reduce adhesion from proteins, ${ }^{27,28}$ bacteria, ${ }^{29,30}$ blood platelets, plasma and serum, ${ }^{31-33}$ and algae. ${ }^{34}$ Current methods of preparing zwitterionic coatings usually involve tethering polymers to surfaces via covalent reaction with available surface chemistries. However, functionalization of substrates that do not offer reactive surface groups remains a challenge. 
It is postulated that combining the known anti-adhesive properties of hydrophilic materials with control over nanotopographies within a coating, could enhance reduction in fouling across a broader range of fouling species. Thus, we have chosen to investigate the antifouling behaviour of coatings prepared from silica nanoparticles (SiNPs) of various sizes in combination with hydrophilic zwitterionic chemistries. The roughness and surface area of the SiNPs coatings could be easily tuned through variation in particle size, while the SiNPs themselves are naturally hydrophilic and provide a reactive surface for the tethering of hydrophilic chemistries. In our previous work, we reported that coatings of zwitterion modified $12 \mathrm{~nm}$ SiNPs presented excellent antifouling properties. ${ }^{35}$ Varying SiNP size was not only anticipated to change the coating morphology but also influence chemistry organisation and grafting density on the nanoparticle surface, as demonstrated in previous studies. ${ }^{36-38}$ The optimal reaction conditions determined from previous work were employed to functionalize SiNPs ranging from 7 to $75 \mathrm{~nm}$ with zwitterionic sulfobetaine and coatings of SiNPs were prepared via a simple spin-coating process. The effect of particle size on the coatings' antifouling properties was investigated by comparing protein adsorption, bacterial adhesion and fungal spore binding to coatings prepared from differently sized particles.

\section{Experimental}

\section{Materials}

LUDOX@ HS-40 colloidal silica, 1,3-propanesultone, (N,N-dimethylaminopropyl)trimethoxysilane, acetone (270725), hydrophobin SC3 (68795), bovine serum albumin (A-3059), and phosphate buffered saline (PBS) were purchased from Sigma-Aldrich. Bindzil 30/360, Levasil CT13M, Levasil CT8PL, and Levasil 30/50 were supplied by AkzoNobel. Acetone

was dried with $3 \AA$ molecular sieves and distilled before use. All other reagents purchased from commercial suppliers were used without further purification. Water used in experiments and to prepare aqueous solutions was purified using a Millipore water purification system 
with a minimum resistivity of $18.2 \mathrm{M} \Omega . \mathrm{cm}$ at $25{ }^{\circ} \mathrm{C}$.

\section{Synthesis of Zwitterionic Sulfobetaine (SB)}

Sulfobetaine (3-(dimethyl(3-trimethoxysilyl)propyl)ammonio propane-1-sulfonate) (SB) was synthesized following a previously reported procedure. ${ }^{39}$ Briefly, ( $N, N$-dimethylaminopropyl)trimethoxysilane $(2.08 \mathrm{~g}, 0.01 \mathrm{~mol})$ was added to 1,3-propanesultone $(1.22 \mathrm{~g}, 0.01 \mathrm{~mol})$ in anhydrous acetone $(10 \mathrm{~mL})$ under Ar at RT. Reaction was stirred vigorously under Ar for 6 h. The formed precipitate was filtered off and washed several times with anhydrous acetone. The resulting solid was dried at $70{ }^{\circ} \mathrm{C}$ under vacuum overnight and stored under Ar.

Yield 78\%: ${ }^{1} \mathrm{H}$ NMR (400 MHz, $\left.\mathrm{D}_{2} \mathrm{O}\right) \delta 0.69$ (t, 2H), 1.90 (quin, 2H), 2.23 (quin, 2H), $3.00(\mathrm{t}, 2 \mathrm{H}), 3.11(\mathrm{~s}, 6 \mathrm{H}), 3.36(\mathrm{~s}, 9 \mathrm{H}), 3.37(\mathrm{t}, 2 \mathrm{H}), 3.42(\mathrm{t}, 2 \mathrm{H}) ;{ }^{13} \mathrm{C} \mathrm{NMR}\left(400 \mathrm{MHz}, \mathrm{D}_{2} \mathrm{O}\right)$ $\delta 10.9,18.7,20.9,50.0,51.6,53.3,64.9,68.8$.

\section{Reaction of SB to Silica Nanoparticles (SiNPs)}

Reaction of SB to SiNPs of different diameters was performed following the procedure described by Estephan et al.. ${ }^{40}$ The appropriate amount of SB monomer for reaction to each of the different particle sizes was calculated based on the surface area reported by the manufacturer and 4.9 silanol groups per $\mathrm{nm}^{2}$ of silica surface. ${ }^{41} \mathrm{SB}$ was dissolved in $\mathrm{H}_{2} \mathrm{O}$ and the $\mathrm{pH}$ adjusted to 9.5 prior to dropwise addition to stirred nanoparticle solutions. Particle solutions diluted to a final concentration of $10 \mathrm{wt} \%$. Reaction mixtures were stirred for 2 $\mathrm{h}$ at RT, then transferred to $12 \mathrm{~K}$ molecular weight cutoff dialysis membrane and dialysed against pure water. Dynamic light scattering (DLS) and zeta potential (ZP) measurements were performed on a Malvern Zetasizer Nano-ZS at $25{ }^{\circ} \mathrm{C}$ (colloidal silica refractive index: 1.50, absorption: 0.010 , measurement angle: $\left.173^{\circ}\right)$. DLS measurements were carried out on 0.25 wt\% particle solutions dispersed in $0.1 \mathrm{M} \mathrm{NaCl}$. ZP measurements were carried out on 0.25 wt\% particle solutions $\mathrm{pH}$ adjusted with $\mathrm{HCl}$ and $\mathrm{NaOH}$. Thermogravimetric analysis (TGA, Q500) was performed on freeze-dried nanoparticles. Briefly, dried particles 
were heated from RT to $800{ }^{\circ} \mathrm{C}$ at a heating rate of $10{ }^{\circ} \mathrm{C} / \mathrm{min}$ under a nitrogen atmosphere. The mass of polymer bound to the particle surface was calculated from mass losses observed above $200{ }^{\circ} \mathrm{C}$. The mass retained at $800{ }^{\circ} \mathrm{C}$ after polymer decomposition was considered to be the mass of bare particles and was used to calculate grafting density.

\section{Preparation of SiNP Coatings}

SiNP coatings were prepared onto gold coated coverslips and onto A-T cut quartz crystal microbalance sensors with a $10 \mathrm{~mm}$ diameter gold electrode and a fundamental resonance frequency of $5 \mathrm{MHz}$. Prior to coating, the gold surface of each crystal was cleaned with piranha solution (7:3 v/v mixture of $\mathrm{H}_{2} \mathrm{SO}_{4}(98 \%)$ and $\left.\mathrm{H}_{2} \mathrm{O}_{2}(33 \%)\right)$ for 3 minutes, rinsed with deionized water and dried in a stream of nitrogen gas. Cleaned surfaces were then incubated in $0.5 \%$ poly(ethyleneimine) (PEI) solution for 10 minutes at RT to form an adhesive layer. PEI was thoroughly rinsed from the surfaces with deionized water and surfaces were dried in a stream of nitrogen gas. SiNP solutions were prepared as 4 wt\% dispersions in water for spin-coating. Coverslips and sensors were mounted into the spincoater and particle films were prepared by depositing 20-50 $\mu \mathrm{L}$ of the 4 wt $\%$ suspensions onto their surface and spin-coating at 5000 RPM for 30 sec. Coatings were cured for $1 \mathrm{~h}$ at $120{ }^{\circ} \mathrm{C}$ and thereafter thoroughly rinsed with deionized water and dried in a stream of nitrogen gas.

\section{Particle Coating Characterization}

Contact angle measurements were acquired using a Dataphysics Contact Angle System (OCA $15 \mathrm{EC})$ in conjunction with SCA20 software. The mean static contact angle made by a $2 \mu \mathrm{L}$ sessile water droplet in contact with the particle coatings was measured. A minimum of three measurements were obtained for triplicate samples of each particle coatings. The surface morphology of silica nanoparticle coatings were examined using a Parks System Atomic Force Microscopy (AFM), operating in tapping mode with a Mikromash NSC15 cantilever 
(spring constant $\sim 37 \mathrm{~N} / \mathrm{m}$ ). Image scans of $2 \mu \mathrm{m} \times 2 \mu \mathrm{m}$ and $5 \mu \mathrm{m} \times 5 \mu \mathrm{m}$ were obtained at a scan rate of $1 \mathrm{~Hz}$ in air. Surface area and coating roughness were calculated using Gwyddion v.2.4.8. software. Scanning electron microscope (SEM) images were acquired of the particle coatings using a JEOL JSM-7500FA in secondary electron imaging mode.

\section{Quartz Crystal Microbalance (Protein Adsorption)}

Adsorption of protein onto the SiNP coatings was quantified using a quartz crystal microbalance with dissipation monitoring (QCM-D, Q-Sense AB Västra, Frölunda, Sweden). Coatings were prepared onto QCM sensors as described above. Firstly, SiNP coated sensors were placed into standard Q-Sense flow modules (QFM 401) and equilibrated in PBS at a constant temperature of $22.00 \pm 0.02{ }^{\circ} \mathrm{C}$ until the baseline signals stabilized. Bovine serum albumin (BSA) or hydrophobin solutions at concentrations of $1 \mathrm{mg} / \mathrm{mL}$ and $10 \mu \mathrm{g} / \mathrm{mL}$, respectively, were introduced into the QCM chamber at a constant flow rate of $60 \mu \mathrm{L} / \mathrm{min}$. After 30 min, PBS was re-introduced to rinse the coatings and remove any loosely bound proteins. The mass of adsorbed protein was calculated by applying the Voigt model using Q-Sense QTools analysis software v3.0.10.286 (Biolin Sci, AB). All experiments were run in triplicate. The following input parameters provided the best fit for the layer density (1150 $\left.\mathrm{kg} / \mathrm{m}^{3}\right)$, fluid density $\left(1020 \mathrm{~kg} / \mathrm{m}^{3}\right)$, layer viscosity $\left(10^{-6} \leq 10^{-2} \mathrm{~kg} / \mathrm{ms}\right)$, layer shear modulus $\left(10^{4} \leq 10^{8} \mathrm{~Pa}\right)$ and mass $\left(1.15 \leq 1.155 \mathrm{ng} / \mathrm{cm}^{2}\right)$. The third, fifth and seventh overtones were used for modelling calculations.

\section{Bacterial Adhesion Study}

Bacterial solutions were prepared from a pre-cultured JM109 strain of Escherichia coli and inoculated overnight in $10 \mathrm{~mL}$ of sterile LB (Luria-Bertani) medium at $37{ }^{\circ} \mathrm{C}$ in a Bioline incubator shaker 8500 (Edwards Instrument Co., Narellan, Australia). $0.5 \mathrm{~mL}$ of inoculated culture was added to $10 \mathrm{~mL}$ of LB medium and optical density measurements carried out every 30 minutes using a Spectronic 200 (Thermo Scientific, Waltham, MA, USA) until the 
desired turbidity was achieved $\left(\mathrm{OD}_{600}\right.$ 0.6-1.0). The number of colony forming units (CFU) in the bacterial suspension was determined by plating out dilutions of the suspension and was found to be $6.3 \times 10^{6} \mathrm{CFU} / \mathrm{mL}$. Coverslips coated with SiNPs were firstly sterilized by briefly immersing them in EtOH (2 seconds) and then placed into individual wells of sterile 12-well culture plates. $2 \mathrm{~mL}$ of PBS with bacterial cells were added to each well, and culture plates were incubated at $37^{\circ} \mathrm{C}$ for either $2 \mathrm{~h}$ or $24 \mathrm{~h}$ time periods. Coverslips were then removed from incubation, immersed in PBS with agitation (6x), rinsed with $2 \mathrm{~mL}$ PBS and placed into fresh sterile 12-well culture plates. Bacteria were fixed onto coverslips and stained by applying $1 \mathrm{~mL}$ of $20 \mu \mathrm{g} / \mathrm{mL}$ Hoechst 33342 (Invetrogen - Life Technologies (Thermo Scientific)) in a $2.5 \mathrm{wt} \%$ glutaraldehyde solution. Stained bacteria were imaged using a Zeiss AxioImager A1M with an open HBO 100 mercury lamp and an Axiocam MRm camera (Carl Zeiss, Oberkochen, Germany). Images were obtained at 10x magnification, with bacterial counts determined using ImageJ@) software (v.1.50b).

\section{Fungal Spore Adhesion Study}

Adhesion of Epicoccum nigrum (ATCC 42773) fungus to SiNP coatings was evaluated. $E$. nigrum spores were collected from a pre-cultured agar plate (potato dextrose agar (BD 213400)) and dispersed in $7 \mathrm{~mL}$ sterile water. The spore suspension was shaken vigorously and placed on an orbital shaker for 2 hours. The suspension was then centrifuged for 5 minutes at 1500 RPM. The supernatant was removed, and spores were resuspended in $7 \mathrm{~mL}$ sterile water. The spore suspension was then filtered through a $40 \mu \mathrm{m}$ hollander weave mesh to ensure good spore separation and diluted $\sim 10$-fold. Spin-coated nanoparticle coatings were placed into a sterile Greiner 12 well cell culture plate and covered with $1 \mathrm{~mL}$ sterile deionized water. An aliquot of spore suspension was then deposited onto coatings to give a concentration of $2 \times 10^{4}$ spores per $\mathrm{cm}^{2}$ and samples were incubated at $30{ }^{\circ} \mathrm{C}$ for 24 hours. Samples were removed from the incubator after 24 hours and each coverslip was immersed in sterile water $(3 \mathrm{x})$ with gentle agitation, then washed $(3 \mathrm{x})$ with sterile water. Spores were 
fixed with $2.5 \%(\mathrm{v} / \mathrm{v})$ glutaraldehyde solution. Fixed spores were imaged at 5x magnification using a Zeiss Axiovert inverted microscope. Areas imaged were chosen randomly and spores counted using ImageJ(R) software (v.1.50b). A minimum of 5 images were obtained for each sample surface and each surface was sampled in triplicate with the total average reported.

\section{Statistical Analysis}

Results were analyzed using one-way analysis of variance (ANOVA) with Tukey post hoc test. Probabilities of $p<0.05$ were considered to be significantly different. All statistical analyses were performed using IBM SPSS Statistics 21 software.

\section{Results and Discussion}

\section{Particle Functionalization and Characterization}

We selected 5 different silica nanoparticles from commercial suppliers, ranging from 7 to 75 $\mathrm{nm}$ in diameter. All particles were negatively charged, stabilized by a sodium or ammonium counterion, and supplied from the manufacturer in the pH range of $9.1-10.1$ (Table 1). Whilst suspensions containing particles in the range of $7-22 \mathrm{~nm}$ were transparent, suspensions of 30 and $75 \mathrm{~nm}$ particles were opaque.

Table 1: Summary of silica nanoparticle properties as specified by the manufacturer.

\begin{tabular}{lccccc}
\hline Commercial name & $\begin{array}{c}\text { Concentration } \\
(\%)\end{array}$ & $\begin{array}{c}\text { Particle } \\
\text { size }(\mathrm{nm})\end{array}$ & $\begin{array}{c}\text { Surface Area } \\
\left(\mathrm{m}^{2} / \mathrm{g}\right)\end{array}$ & $\mathrm{pH}$ & $\begin{array}{c}\text { Stabilizing } \\
\text { counterion }\end{array}$ \\
\hline Bindzil 30/360 & 30 & 7 & 360 & 10.1 & $\mathrm{Na}^{+} / \mathrm{NH}_{4}^{+}$ \\
Ludox HS-40 & 40 & 12 & 220 & 9.8 & $\mathrm{Na}^{+} / \mathrm{NH}_{4}^{+}$ \\
Levasil CT13M & 30 & 22 & 130 & 9.1 & $\mathrm{Na}^{+} / \mathrm{NH}_{4}^{+}$ \\
Levasil CT8PL & 30 & 30 & 85 & 10.0 & $\mathrm{Na}^{+} / \mathrm{NH}_{4}^{+}$ \\
Levasil 30/50 & 30 & 75 & 35 & 9.5 & $\mathrm{Na}^{+} / \mathrm{NH}_{4}^{+}$ \\
\hline
\end{tabular}

SiNP suspensions were diluted to $10 \mathrm{wt} \%$ prior to reaction with zwitterionic sulfobetaine (SB). SB was dissolved in water and then $\mathrm{pH}$ adjusted to 9.5 to promote hydrolysis of the 
methoxy substituents. Addition of SB to the SiNP suspensions resulted in silanol condensation reactions and covalent binding of SB to the SiNP. No visual changes to the solutions upon reaction were observed. After reaction, unbound monomer was removed via dialysis. To ensure particles remained stable after the reaction procedure, particle size was examined before and after functionalization using dynamic light scattering (Table 2). It was observed that the hydrodynamic diameter $\left(\mathrm{D}_{h}\right)$ of all particles were larger than the nominal particle size indicated by the manufacturer, as this technique also accounts for the hydration sphere of the solvated particles (Figure 1f). Polydispersity measurements revealed that the 22 and $75 \mathrm{~nm}$ particles were monodisperse and the 7, 12, and $30 \mathrm{~nm}$ particles had larger size distributions. Variation in particle size was particularly apparent for the $30 \mathrm{~nm}$ particles, as visualized by scanning electron microscopy of the $30 \mathrm{~nm}$ particle coating (Figure 1d).

Table 2: Hydrodynamic diameter and polydispersity index of particle solutions before and after modification with SB, as measured by dynamic light scattering.

\begin{tabular}{ccccc}
\cline { 2 - 5 } & \multicolumn{2}{c}{ SiNP } & \multicolumn{2}{c}{ SiNP + SB } \\
\hline Nominal Size & $\mathbf{D}_{h}(\mathbf{n m})$ & PDI & $\mathbf{D}_{h}(\mathbf{n m})$ & PDI \\
\hline $7 \mathrm{~nm}$ & $22.2 \pm 0.2$ & 0.124 & $22.2 \pm 0.5$ & 0.158 \\
$12 \mathrm{~nm}$ & $21.8 \pm 0.1$ & 0.129 & $24.6 \pm 0.3$ & 0.119 \\
$22 \mathrm{~nm}$ & $32.1 \pm 0.3$ & 0.025 & $32.2 \pm 0.2$ & 0.033 \\
$30 \mathrm{~nm}$ & $81.6 \pm 0.7$ & 0.145 & $80.9 \pm 1.6$ & 0.137 \\
$75 \mathrm{~nm}$ & $100.7 \pm 0.7$ & 0.019 & $101.3 \pm 1.7$ & 0.015 \\
\hline
\end{tabular}

After functionalization, very little to no change in particle size was observed. This is likely due to the small size of the SB monomer $(\sim 1.2 \mathrm{~nm})$ and the particles already presenting a high degree of solvation prior to functionalization. This result confirmed that no particle aggregation occurred during functionalization and that particle suspensions were stable and well dispersed.

The degree of particle functionalization was quantified using thermogravimetric analysis. Mass losses above $200{ }^{\circ} \mathrm{C}$ were attributed to SB decomposition (mass losses at lower temperatures are likely from adsorbed water). Percentage mass losses were found to increase with decreasing particle size due to smaller particles presenting higher surface areas (Table 3). 
However, calculation of surface coverage, factoring in surface area and theoretical number of silanol groups available for reaction $\left(8.14 \mu \mathrm{mol} / \mathrm{m}^{2}\right.$ or 4.90 molecules $\left./ \mathrm{nm}^{2}\right),{ }^{41}$ revealed that the larger particles (in fact) presented the highest degree of particle functionalization.

For all particle modifications, the quantity of SB added was equivalent to theoretical saturation of all available silanol sites on the particle surfaces. However, only 8 - $18 \%$ of sites were calculated to have been functionalized. This result is consistent with previous studies where maximum silanol functionalizations of $\sim 25 \%$ have been achieved. ${ }^{40,42}$

Table 3: Surface coverage of SB modification calculated from mass loss observed during thermogravimetric analysis.

\begin{tabular}{ccccc}
\cline { 2 - 5 } Particle & \multicolumn{4}{c}{ Surface Coverage } \\
Size & $\begin{array}{c}\text { Surface Area } \\
\left(\mathbf{m}^{2} / \mathbf{g}\right)\end{array}$ & $\begin{array}{c}\text { Mass Loss } \\
(\boldsymbol{\%})\end{array}$ & $\mu \mathbf{m o l} / \mathbf{m}^{2}$ & $\mathbf{m o l e c u l e s} / \mathbf{n m}^{2}$ \\
\hline $7 \mathrm{~nm}$ & 360 & 5.79 & 0.63 & 0.38 \\
$12 \mathrm{~nm}$ & 220 & 5.69 & 0.99 & 0.60 \\
$22 \mathrm{~nm}$ & 130 & 4.31 & 1.24 & 0.75 \\
$30 \mathrm{~nm}$ & 85 & 3.31 & 1.45 & 0.87 \\
$75 \mathrm{~nm}$ & 35 & 1.14 & 1.16 & 0.70 \\
\hline
\end{tabular}

Despite the larger surface area presented by smaller SiNPs, the 7 and $12 \mathrm{~nm}$ particles experienced the lowest degree of functionalization. As all functionalization reactions were carried out at particle concentrations of $10 \mathrm{wt} \%$, the relative amount of silane addition increased dramatically with decreasing particle size. This increase in silane concentration, in combination with alkaline conditions which favour rapid hydrolysis and condensation reactions, was thought to promote self-condensation reactions and oligomer formation, thus reducing the amount of silane available to react to the particle surface. ${ }^{43}$ Additionally, the number of silanol groups per unit area of silica is proposed to decrease with decreasing particle size due to incomplete or retarded formation of silanol groups at the surface of smaller silica nanoparticles. ${ }^{44}$ This could lead to an underestimation of the total possible degree of particle functionalization for the smaller SiNPs.

The surface charge of SiNPs was characterized by measuring the zeta potential (ZP) of particle dispersions across the pH range of 3.0 - 11.0 (Figures S2/S3). Overall, particle 
dispersions presented negative $\mathrm{ZP}$ values due to the presence of deprotonated silanol groups. Decreasing $\mathrm{pH}$ had the effect of increasing the ZPs as a higher proportion of surface groups became protonated. The larger 30 and $75 \mathrm{~nm}$ particles presented slightly more negative overall ZPs. This result is consistent with previous reports where larger particles have demonstrated increased acidity due to a higher fraction of vicinal silanol groups and a higher proportion of ionized silanol groups. ${ }^{45}$ Functionalization of SiNPs with SB did not drastically alter the ZP profile across the pH range studied. Slightly higher ZPs were recorded with SB modification due to occupation of some silanol/siloxide sites, however the overall surface charge remained largely unchanged.

\section{Coating Preparation and Characterization}

Particle coatings were prepared via a simple spin-coating process. Particle suspensions were diluted to 4 wt\%, deposited onto PEI coated gold QCM sensors and gold-coated glass coverslips, and spun at 5000 RPM for a period of 30 seconds. Scanning electron microscopy images revealed that spin-coating produced homogenous particle coatings from a single deposition of particle suspensions for the 7, 12, and $22 \mathrm{~nm}$ particle sizes (Figure 1a-c). A second layer of spin-coated particles was required to ensure complete surface coverage of the larger 30 and $75 \mathrm{~nm}$ particles (Figure 1d-e).

Surface energy and roughness are two factors known to influence the wettability of surfaces. Additionally, these parameters can have a pronounced effect on the antifouling behaviour presented by an interface. For this reason, SiNP coating wettability was investigated by measuring surface water contact angles, and coating roughness was probed using atomic force microscopy (AFM). We observed that control (unmodified) particle coatings all presented low static water contact angles $\left(<15^{\circ}\right)$, indicating hydrophilic properties at the coating interface (Table 4.). Whilst substrates presenting similar surface chemistry, such as glass, require $\mathrm{UV} / \mathrm{O}_{3}$ or plasma cleaning to generate increased surface hydrophilicity, ${ }^{46}$ these SiNP coatings presented exceptional hydrophilicity without exposure to any form of surface 

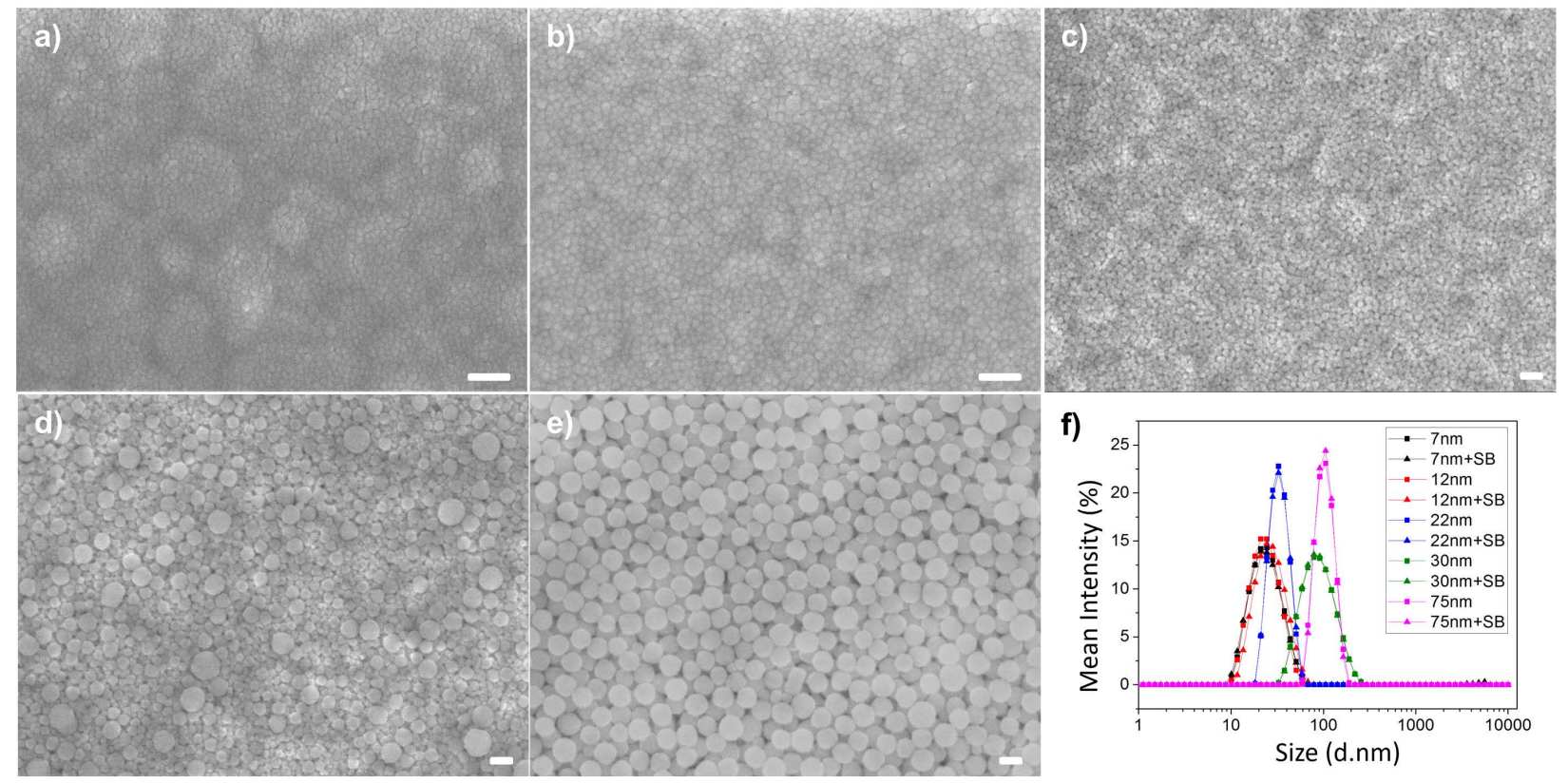

Figure 1: Scanning electron microscope images of SB modified SiNP coatings of particle size: $7 \mathrm{~nm}$ (a), $12 \mathrm{~nm}$ (b), $22 \mathrm{~nm}$ (c), $30 \mathrm{~nm}$ (d), and $75 \mathrm{~nm}$ (e) (scale bars are $100 \mathrm{~nm}$ ), and hydrodynamic diameter of particles before and after modification using dynamic light scattering (f).

treatment. SiNP surface chemistry is expected to play a role here, with particles presenting an abundance of protonated $(\mathrm{Si}-\mathrm{OH})$ and/or deprotonated $\left(\mathrm{Si}_{-} \mathrm{O}^{-}\right)$silanol groups available to interact with water through hydrogen bonding or ionic solvation, respectively. ${ }^{47}$ In addition to the surface chemistry presented by the SiNP coatings, it is also anticipated that the nanoscaled surface topography would further enhance surface hydrophilicity, as described by the Cassie-Baxter equation. ${ }^{48}$

Coatings prepared from zwitterion modified SiNPs presented a higher degree of hydrophilicity than their unmodified coating controls. For all SB modified SiNP coatings, contact angles were reduced to $<8^{\circ}$, indicating zwitterion chemical addition had a stronger influence on coating hydrophilicity than the SiNP size. This result was anticipated, as the strong hydration capacity of zwitterionic polymers is well documented, ${ }^{49,50}$ and the change in coating contact angles (on addition of SB) was small due to the inherent hydrophilicity of the SiNPs. 
Table 4: Roughness $\left(\mathrm{R}_{q}\right)$ and surface area of SB modified SiNP coatings as calculated from $5 \mu \mathrm{m} \times 5 \mu \mathrm{m}$ AFM scans. Contact angles of control (unmodified) and SB modified SiNP coatings (95\% confidence intervals).

\begin{tabular}{ccccc} 
& \multicolumn{2}{c}{ Surface Properties } & \multicolumn{2}{c}{ Contact Angle $\left(^{\circ}\right)$} \\
\hline $\begin{array}{c}\text { Particle } \\
\text { Size }\end{array}$ & $\mathbf{R}_{q}(\mathbf{n m})$ & $\begin{array}{c}\text { Surface } \\
\text { Area }\left(\mu \mathbf{m}^{2}\right)\end{array}$ & Control & SB Modified \\
\hline $7 \mathrm{~nm}$ & $2.82 \pm 0.56$ & $25.09 \pm 0.02$ & $7.8 \pm 2.9$ & $7.6 \pm 1.4$ \\
$12 \mathrm{~nm}$ & $3.18 \pm 0.22$ & $25.20 \pm 0.03$ & $9.0 \pm 2.6$ & $7.0 \pm 1.3$ \\
$22 \mathrm{~nm}$ & $3.04 \pm 0.31$ & $25.20 \pm 0.05$ & $14.8 \pm 3.5$ & $6.5 \pm 0.5$ \\
$30 \mathrm{~nm}$ & $19.34 \pm 1.16$ & $28.52 \pm 0.72$ & $10.0 \pm 3.3$ & $5.8 \pm 2.1$ \\
$75 \mathrm{~nm}$ & $17.80 \pm 1.11$ & $28.58 \pm 0.81$ & $11.2 \pm 1.1$ & $7.5 \pm 1.2$ \\
\hline
\end{tabular}

In addition to surface wettability, the effect of particle size on coating roughness was also of interest. AFM scans revealed that the SiNP coatings presented nanoscaled surface features and a size dependant variation in coating roughness (Table 4$)$. Image scans $(5 \mu \mathrm{m} \times 5 \mu \mathrm{m})$ of 7, 12, and $22 \mathrm{~nm}$ particle coatings displayed very small increases in contactable surface area and nanometre root mean square surface roughness $\left(\mathrm{R}_{q}\right)$. A much larger increase in both surface area and $\mathrm{R}_{q}$ roughness were observed for the larger 30 and $75 \mathrm{~nm}$ particle coatings. Interestingly, the $30 \mathrm{~nm}$ particle coating presented the highest roughness. This is likely the result of this particle's larger size distribution, as observed by DLS/PDI measurements and SEM observations (Figure 1d \& f).

While $\mathrm{R}_{q}$ measurements provide an insight into overall coating roughness, they are not a good indicator of true surface topography as they do not account for variation in lateral roughness and profile skewness. ${ }^{51}$ Differences in SiNP coating morphology are more easily observed in the 3D AFM scans presented in Figure 2. The $\mathrm{R}_{a}$ values presented are again similar for the three smaller particle coating scans $(2 \mu \mathrm{m} \times 2 \mu \mathrm{m})$, however, differences in the height and spacing of features are much more pronounced. Cross-sectional coating profiles further illuminate the dramatic change in dimension of surface features with increasing particle size.

Although the topographic features generated from the deposition of SiNPs are random, the overall scale and arrangement of surface features appears fairly consistent for each particle 
a)

b)

c)

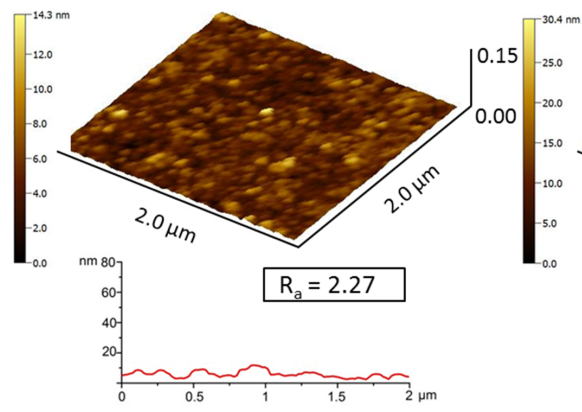

d)
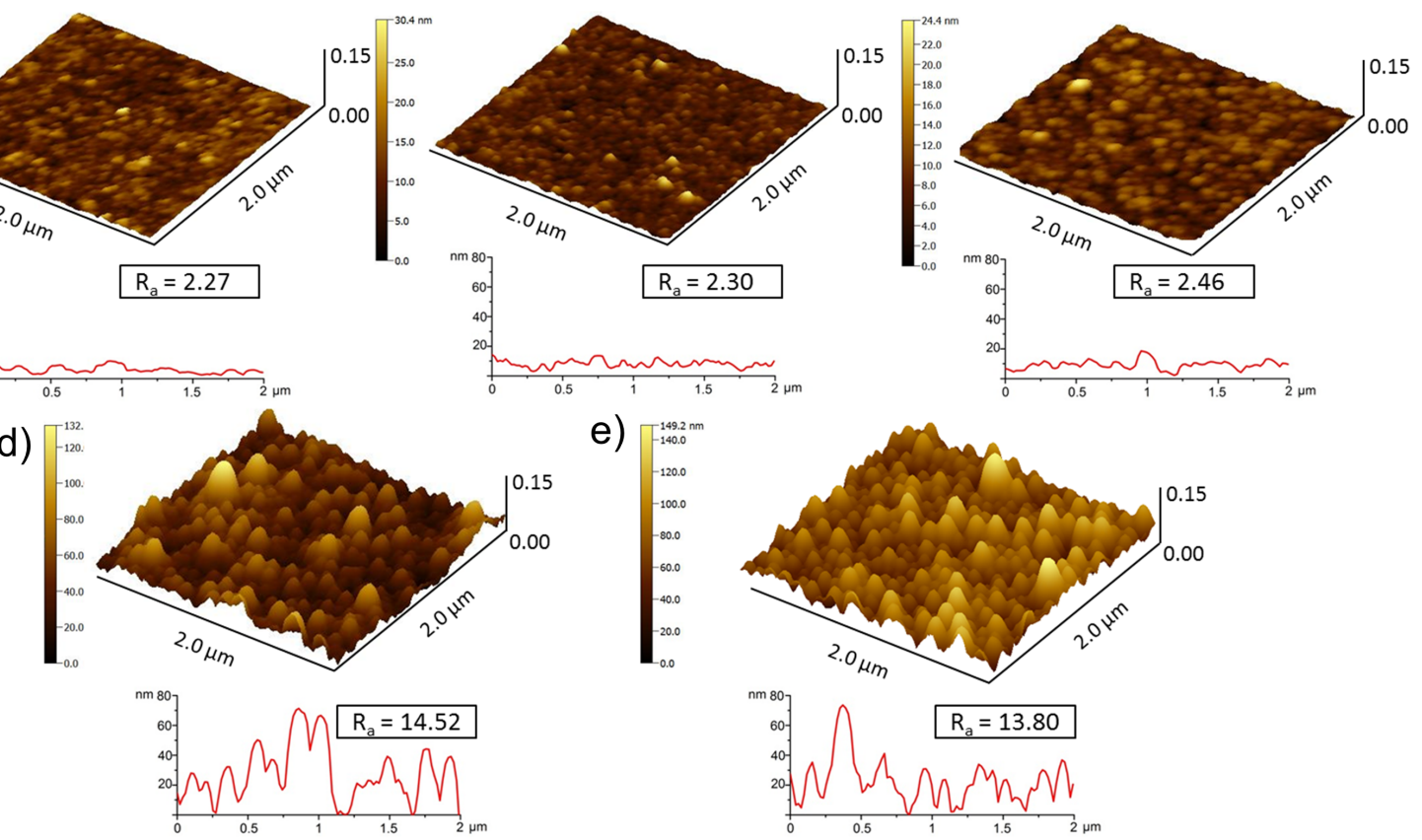

e)
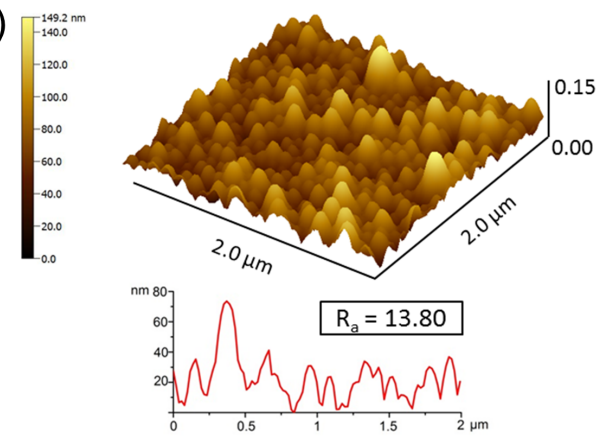

Figure 2: 3D AFM scans $(2 \mu \mathrm{m} \times 2 \mu \mathrm{m})$ and cross-sectional profile of SB modified SiNP coatings of particle diameter: $7 \mathrm{~nm}$ (a), $12 \mathrm{~nm}$ (b), $22 \mathrm{~nm}$ (c), $30 \mathrm{~nm}$ (d), and $75 \mathrm{~nm}(\mathrm{e})$.

size. This highlights the ease with which we can very simply prepare and tune the nanoscaled surface topography presented at an interface.

\section{Antifouling Assessment}

Despite immense interest in the field of scaled topographies for fouling prevention, relatively few studies have explored engineered topography on the nanoscale. Most work presented in the literature has focused on the generation of surface topographies with similar dimensions to the fouling species of interest, as this has been demonstrated to drastically influence adhesion. ${ }^{18,52,53}$ However, while organisms such as bacteria have dimensions in the micrometre size range, their surface appendages and adhesive structures are in the nanometre range. ${ }^{54}$ This highlights the need for control of surface topography at both the nano- and micro-scale for effective prevention of biological fouling.

Recent advances in the generation of nanoscale surface features using lithographic or 
chemical patterning techniques (see Anselme et al. for review) ${ }^{51}$ have allowed for the fabrication of intricately patterned substrates with high degrees of spatial resolution. However, there is often a trade-off between the expense, resolution, and time taken to prepare surfaces depending on the choice of patterning technique. In this work, the preparation of coatings through the deposition of differently sized SiNPs has allowed for the simple fabrication of nanoscaled interfacial patterning. We have examined the effect of nanoscaled features on adsorption and adhesion of fouling species with dimensions ranging over several orders of magnitude.

\section{Protein Adsorption}

Protein adsorption is a key process in the formation of biofilms as bacteria and cellular interactions with a substrate are mediated by the presence of a surface conditioning film, comprised of adsorbed proteins, glycoproteins, and polysaccharides. ${ }^{51,55}$ Therefore, by understanding protein interactions with surfaces, we can further elucidate the effect of nanoscale surface topography on fouling processes. The binding of BSA and hydrophobin proteins to unmodified and SB modified SiNP coatings were investigated using QCM-D. BSA is a globular protein $(66 \mathrm{kDa}, \sim 14 \mathrm{x} 4 \mathrm{~nm})$ commonly used as a model protein in fouling studies, and hydrophobin is a small globular amphiphilic protein $(7.2 \mathrm{kDa}, \sim 3 \mathrm{~nm})$ found on the outer surface of fungal spores and hyphae that assists adhesion to surfaces. ${ }^{56,57}$

Examples of typical QCM-D frequency and dissipation responses for the $22 \mathrm{~nm}$ control and SB modified coatings on exposure to protein are shown in Figure 3. Similar responses were recorded for all other particle sizes. Control coatings experienced large negative $\Delta f$ shifts on exposure to protein solutions at time zero, indicating adsorption to the coating surface. Binding of BSA was rapid, reaching a plateau within the 30 min exposure period. Only a small positive frequency shift was observed upon rinsing with PBS, indicating that majority of protein was irreversibly bound to the coating surface. Binding of hydrophobin to the control coating was more gradual and resulted in a smaller overall $\Delta f$ shift compared to 
BSA. Hydrophobins are known to self-assemble onto hydrophilic-hydrophobic interfaces by undergoing conformational changes that promote favourable surface interactions. ${ }^{58}$ However, as both the protein containing solution and coating interface are hydrophilic; binding rates may have been slowed due to conformational rearrangement to present less of the hydrophobic domain. Alternatively, adsorption may occur in bilayers, lowering the interfacial energy gap. ${ }^{57}$
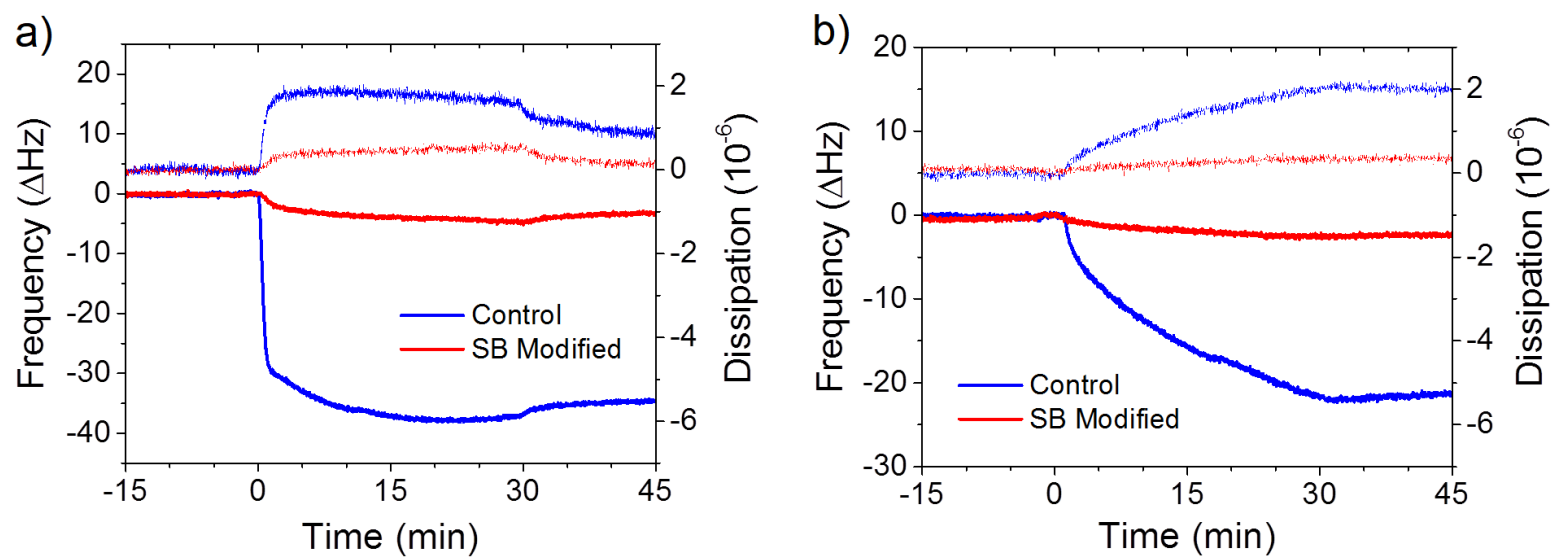

Figure 3: Example QCM-D $\Delta f$ and dissipation shifts of $22 \mathrm{~nm}$ Control and SB Modified SiNP coatings on exposure to BSA (a) and hydrophobin (b).

QCM-D frequency and dissipation shifts were converted to mass of adsorbed protein by applying Voigt modelling (Figure 4). Mass adsorption per unit area was then normalised to coating surface area based on the AFM measurements presented above (ratio: adsorption $\mathrm{x}$ (calculated area/actual area)). Interestingly, no significant difference in binding of BSA protein was observed onto the unmodified control surfaces prepared from different sized SiNPs, although there appeared to be a trend of increasing SiNP size resulting in decreased BSA adsorption (Figure 4a).

It has been reported previously that BSA will undergo conformational changes when interacting with substrate curvature. Roach et al. demonstrated that BSA undergoes drastic changes in conformation upon adsorption onto large silica spheres, with loss of secondary structure and an increase in random coil/extended chain structure. ${ }^{59}$ Smaller particles with larger surface curvature support albumin in a more native-like structure, which could assist 
protein assembly and contribute to the slightly higher adsorptions reported here.
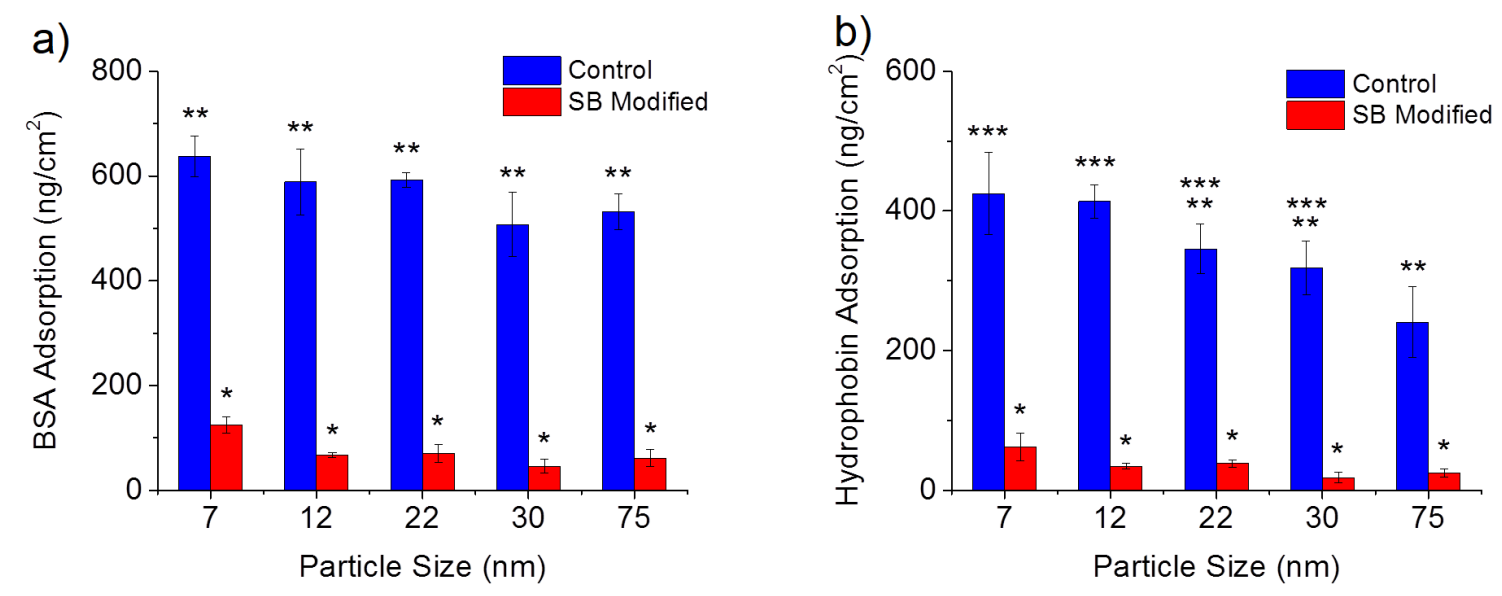

Figure 4: Mass of BSA protein (a) and hydrophobin protein (b) adsorbed onto SiNP coatings with and without SB modification. Adsorbed mass calculated by applying Voigt modelling to raw frequency $(f)$ and Dissipation $(D)$ shifts observed during QCM-D measurements. Error bars represent 1 SD from the mean. Asterisks $\left(^{*}\right)$ denote statistically similar subsets.

Adsorption of BSA was also measured onto a planar surface presenting the same surface chemistry as the SiNPs ( $\mathrm{SiO}_{2}$ QCM sensor). The roughness of this surface was measured by AFM (Figure S4) and found to be less than any of the nanoparticle coatings $\left(\mathrm{R}_{q}=2.50 \mathrm{~nm}\right)$. Additionally, BSA adsorption was slightly less on this surface than for any of the SiNP control coatings $\left(531 \mathrm{ng} / \mathrm{cm}^{2}\right)$. This indicates that the increased surface area and topographical features imparted by particle curvature may enhance protein uptake. Similar results have been presented in other studies, where nanostructured features on polyurethane and titanium have increased protein binding compared to smooth surfaces of the same material. ${ }^{60,61} \mathrm{SB}$ modification was able to significantly reduce protein binding across the range of particle sizes studied, indicating that changes to surface chemistry and energy (water structuring) have a more significant impact on binding than the presence of nanoscaled topographical features (Figure 4a).

Adsorption of hydrophobin protein to SiNP coatings revealed a similar trend to that presented by BSA (Figure 4b). Hydrophobin adsorption decreased onto coatings as particle size increased, with significantly less protein found to adsorb onto the $75 \mathrm{~nm}$ control coatings 
compared to the 7 and $12 \mathrm{~nm}$ SiNP surfaces. The conformational flexibility of hydrophobin is well documented, with hydrophobins known to undergo conformational changes to promote self-assembly onto surfaces. ${ }^{62}$ Additionally, hydrophobins assemble into rodlets consisting of 4 molecule bilayer bundles, with the spacing between rodlets (measured between the tops of two successive fibres) in the range of $8-13 \mathrm{~nm} .{ }^{63}$ It is unlikely that this spacing would be greatly perturbed by the small increase to surface roughness presented by the smaller SiNP coatings. However, the topographical features presented by the larger particles may disrupt the rodlet organisation at the coating interface and thus lower the overall protein uptake.

Despite hydrophobins ability to bind to both hydrophilic and hydrophobic surfaces through presentation of like (hydrophilic/hydrophobic) domains, modification of SiNPs with hydrophilic SB still resulted in dramatic reductions in hydrophobin adsorption (Figure 4b). Again, the presentation of the zwitterionic molecules had a much more dramatic effect on protein adsorption than the size of the particle to which it was attached. There were no significant differences in hydrophobin adsorption between the SB modified SiNP coatings.

\section{Bacterial Adhesion Study}

The effect of nanoscale topography on cellular adhesion is a growing area of research, both in the interest of enhancing cell growth and proliferation, and in the prevention of cellular attachment. The $E$. coli investigated in this study have dimensions in the range of $\sim 0.5 \mathrm{x}$ $2.0 \mu \mathrm{m}$, however, the adhesion of $E$. coli to surfaces is mediated by filamentous organelles and adhesive secretions that are much smaller than the organism itself. Pili and fimbria are organelles anchored to the outer bacterial membrane, ranging from $2-6 \mathrm{~nm}$ flexible hair-like filaments to 6 - $8 \mathrm{~nm}$ stiff rod-like filaments. ${ }^{64}$ These structures are accompanied by adhesins, specialised adhesive proteins that mediate attachment to abiotic surfaces. ${ }^{65}$

The presence of these adhesive mechanisms operating at different scales is likely to influence the interaction behaviour of the bacteria with the nanoparticle surfaces. For the short-term adhesion assay performed over $2 \mathrm{~h}$ (Figure 5a), significantly less bacteria adhered 
to coatings of the larger 30 and $75 \mathrm{~nm}$ control (unmodified) coatings than on to coatings prepared from 7 and $12 \mathrm{~nm}$ SiNP coatings. The $22 \mathrm{~nm}$ SiNP surfaces presenting an intermediate level of bacterial binding. This indicates that the surface topography presented by the different sized SiNPs influenced the adhesion of $E$. coli to the coated surfaces.
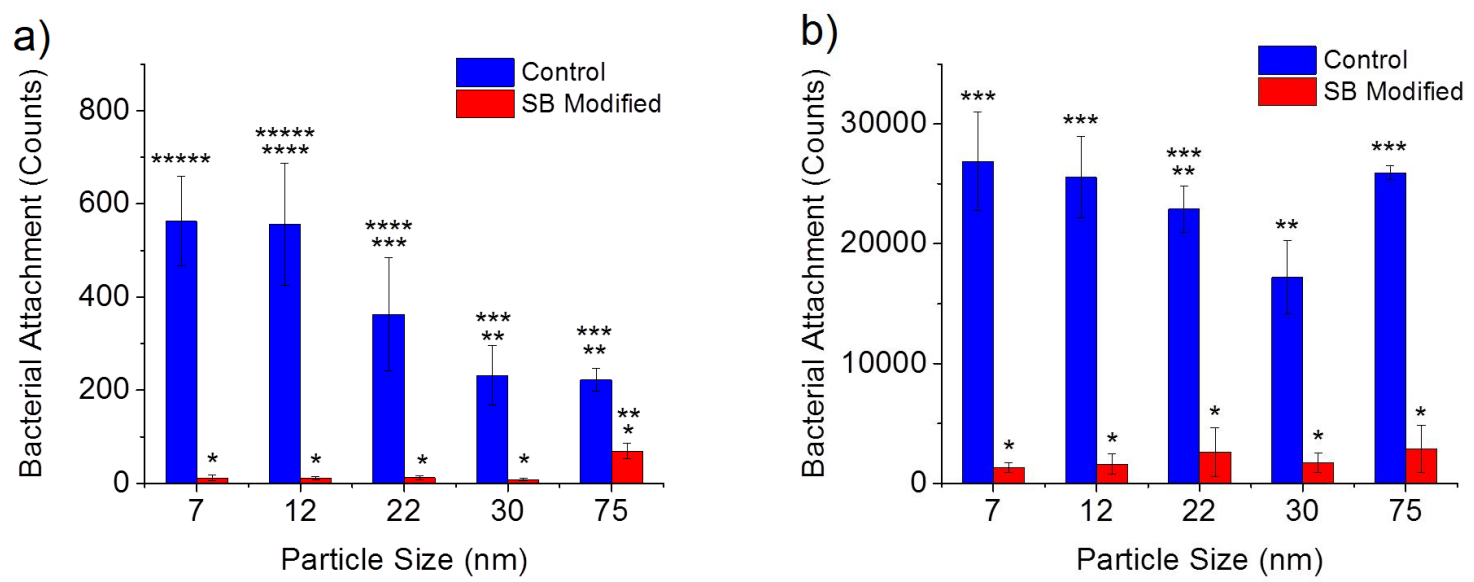

Figure 5: Bacterial attachment to SB modified SiNP coatings compared to control coatings after $2 \mathrm{~h}$ (a) and $24 \mathrm{~h}(\mathrm{~b})$. Error bars represent $1 \mathrm{SD}$ from the mean. Asterisks $\left(^{*}\right)$ denote statistically similar subsets.

This result is in agreement with previous studies, where the presence of nanoscaled surface features produced a reduction in bacterial adhesion. Mitik-Divena et al. demonstrated that bacterial attachment onto nano-rough glass was reduced compared to chemically etched, nano-smoother glass surfaces. ${ }^{66}$ Similarly, Rizzello et al. demonstrated that E. coli adhesion was reduced onto a nanorough gold substrate compared to a flat control surface. ${ }^{67} \mathrm{It}$ appears that not only the presence of nanoscaled features but their size, heavily influences interactions. Analogous to the results presented here, Dalby et al. demonstrated differences in cellular response to nanometric islands prepared by polymer demixing. ${ }^{68}$ For islands of 13, 35, and $95 \mathrm{~nm}$ in height, cell spreading and proliferation was highest on $13 \mathrm{~nm}$ islands and lowest on $95 \mathrm{~nm}$ islands, with significant differences observed in cell morphologies depending on their interactions with the island features. Comparing the control SiNP surfaces to their respective SB modified coatings, all particle sizes experienced reductions in bacterial adhesion (Figure 5a). These reductions were found to be statistically significant $(p<0.05)$ 
for SB modified 7, 12, 22, and $30 \mathrm{~nm}$ SiNP coatings. The $75 \mathrm{~nm} \mathrm{SB}$ modified particles still exhibited a reduction in bacterial adhesion but the result was not significantly less than the unmodified control coating (likely due to the lower adhesion presented by the control group).

While significant differences in bacterial adhesion were observed amongst the control group for the $2 \mathrm{~h}$ study, less variation was presented after $24 \mathrm{~h}$ (Figure 5b). Unmodified 22 and $30 \mathrm{~nm}$ SiNPs experienced the smallest degree of bacterial fouling amongst the control group, while it appears the topographical effects exhibited by the $75 \mathrm{~nm}$ coatings were unable to produce a pronounced anti-adhesion effect over the longer-term study. Bacteria are well known to secrete extra cellular adhesives in response to their arrival and adhesion to a surface. ${ }^{69}$ The deployment of these adhesives, over time, is likely to modify both the chemical and topographic characteristics of the surface, masking the native surface and providing a more favourable surface for the maintenance and growth of bacteria. This process likely contributes to the diminished fouling resistant properties of the unmodified SiNPs after 24 hr observed here. In the case of SB modified SiNP coatings, particle zwitteration had the desired effect of drastically reducing adhesion of bacteria (Figure 5b). However, no significant difference was observed across the different particle sizes studied for all SB modified SiNPs.

\section{Fungal Spore Adhesion}

Fungi are opportunistic foulers that are well adapted for growth on surfaces. ${ }^{70}$ Fungal contamination and colonisation can result in food spoilage and the bioterioration of materials, and may also present allergenic and pathogenic risks. ${ }^{71}$ Fungal fouling is usually combatted through the application of harmful fungicides, while adhesion prevention approaches have not been widely studied. Only a low percentage of the total number of fungal spores that settle onto a habitable substrate will attach, therefore, coatings that could minimise spore adhesion would be beneficial in lowering overall fungal growth and proliferation. The E. nigrum examined here is a prolific surface fouler, forming dense 'mats' and reproducing through the generation of spores. Spores are approximately $10 \mu \mathrm{m}$ in size and rely on a combination 
of surface texture and secreted adhesives (e.g. hydrophobins) to promote their attachment. Hydrophobin proteins assemble at the air-water interface, lowering water surface tension and facilitating attachment of the spore to surfaces. Our protein adsorption study indicated a slight reduction in binding with increasing particle size but significant reductions across all particle sizes when modified with SB. A similar trend was observed when comparing overall spore attachment (Figure 6).
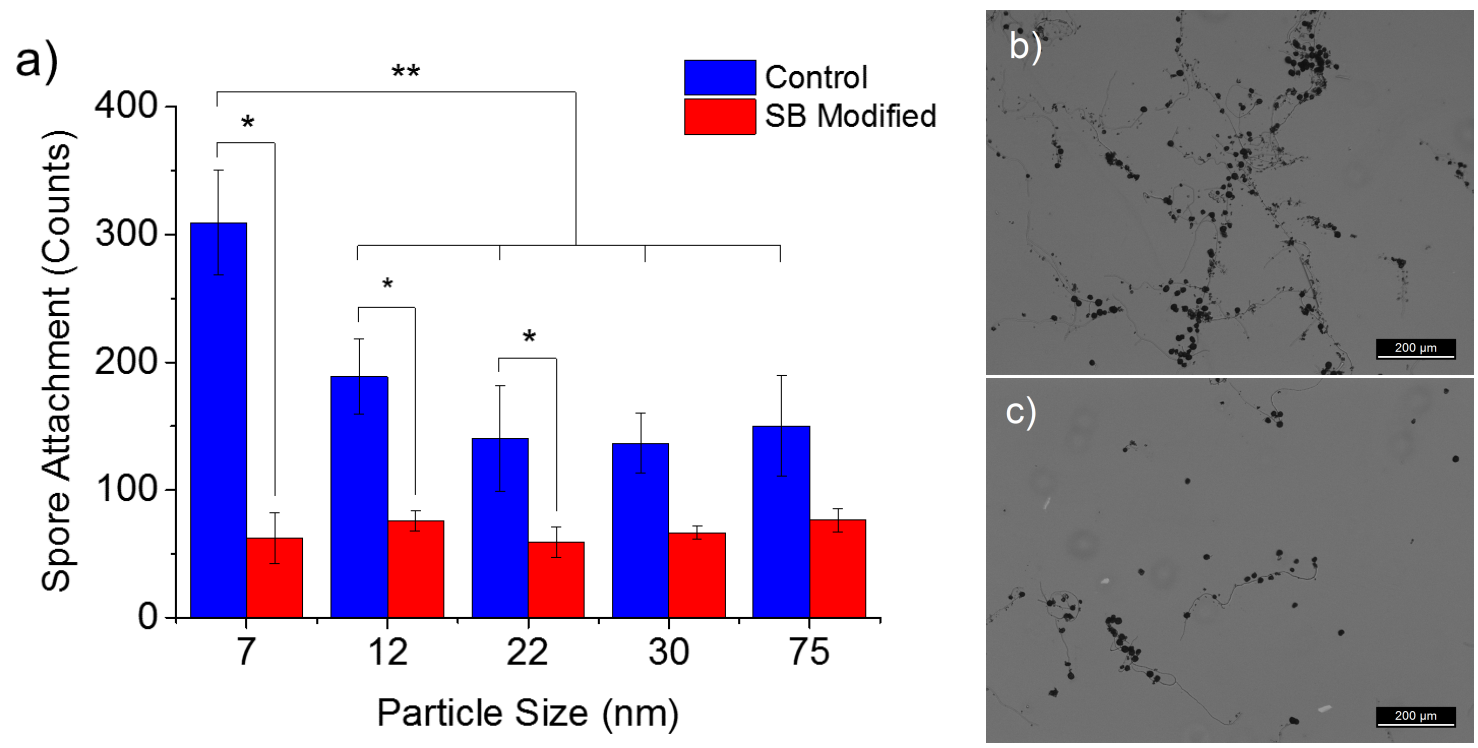

Figure 6: E. nigrum attachment to SiNP coatings after $24 \mathrm{~h}$ incubation (a). Error bars represent 1 SD. Asterisks $(*)$ denote statistically different subsets. Representative images of spore attachment onto $22 \mathrm{~nm}$ coatings without (b) and with (c) SB modification.

The $7 \mathrm{~nm}$ SiNP coating experienced the worst degree of fungal fouling, with significantly higher spore counts compared to any of the other unmodified control surfaces $(p<0.05)$. SB modified $7 \mathrm{~nm}$ particle coatings brought about the largest reduction in spore adhesion (80\%), while 12 and $22 \mathrm{~nm}$ modified particle coatings also showed significant reductions in spore attachment. There was no statistically significant reduction in spore attachment for SB modified 30 and $75 \mathrm{~nm}$ coatings, however, these coatings still halved the number of spore counts compared to their respective controls. While these reductions were not as large as those seen for the protein and bacteria studies, hyphae growth was also reduced on the SB modified coatings (Figure 6c). This would lower the spore's overall adhesion strength and 
potentially allow for spores to be removed by shear forces or gentle mechanical cleaning.

It was anticipated that the antifouling assessment of SiNP coatings would reveal differences in their ability to inhibit biological fouling due to differences in surface nanotopography and chemical functionalization (grafting density and organization). Unmodified SiNP coatings did present differences in their ability to prevent fouling as a result of surface topographic effects, with increasing particle size and coating roughness correlating with improved fouling resistance. In contrast, all functionalized particle coatings showed drastic improvements in fouling prevention regardless of particle size and coating topography. It may be noted that functionalized particles presented non-identical surface coverage (Table 3) and yet there were no observable differences in antifouling performance. This was attributed to lower grafting densities on smaller particles presenting higher masses of bound SB due to increased surface area. In this way, there appears to be a trade-off between increased surface coverage and increased mass of SB incorporated into SiNP coatings. Despite these differences, all SB functionalized SiNP coatings were shown to protect surfaces from fouling, highlighting the versatility this system offers in terms of coating fabrication; where coatings could be tailored to suit particular applications through choice of particle size.

\section{Conclusions}

The simple fabrication of hydrophilic SiNP coatings with tuneable nanoscaled surface topography is reported. The roughness and topography of coatings could be easily adjusted through variation of particle size, while the nanoparticle surface chemistry lent itself to easy functionalization with the zwitterionic, sulfobetaine moiety. This study has demonstrated that nanoscaled topography influences interaction and adhesion of a range of fouling species with proportions spanning several orders of magnitude. Zwitterion functionalization of SiNPs imparted a high degree of fouling resistance across all particle sizes and across the range of proteins and microbial organisms studied. In contrast, unmodified particle coat- 
ings presented size dependent differences in their ability to resist fouling. In most instances, the 22, 30, and $75 \mathrm{~nm}$ particle coatings offered superior resistance to fouling compared the smaller 7 and $12 \mathrm{~nm}$ SiNP surfaces. Overall, this work has demonstrated the ease with which zwitterionic interfaces with modulated topography can be prepared and their potential for widespread application as antifouling surface coatings.

\section{Acknowledgement}

The authors gratefully acknowledge funding from the Australian Research Council Industrial Transformation Research Hubs Scheme (Project Number IH130100017) and thank the ARC Centre of Excellence for Electromaterials Science (CE140100012) and the Australian National Nanofabrication Facility - Materials Node for equipment use. The authors acknowledge use of the facilities and the assistance of Dr. Tony Romeo at the UOW Electron Microscopy Centre. This research has been conducted with the support of the Australian Government Research Training Program Scholarship and M.J.H. acknowledges an Australian Research Council Fellowship (DP110104359).

\section{Supporting Information Available}

The following files are available free of charge.

- FigureS1: Schematic of SiNP functionalization with zwitterionic SB.

- FigureS2: ZP measurements performed on SiNP dispersions between pH 3.0 and 11.0.

- FigureS3: ZP measurements performed on SiNP+SB dispersions between pH 3.0 and 11.0 .

- FigureS4: Example AFM scan $(2 \mu \mathrm{m} \times 2 \mu \mathrm{m})$ of a $\mathrm{SiO}_{2} \mathrm{QCM}$ sensor. 


\section{References}

(1) Yebra, D. M.; Kiil, S.; Dam-Johansen, K. Antifouling Technology - Past, Present and Future Steps Towards Efficient and Environmentally Friendly Antifouling Coatings. Prog. Org. Coat. 2004, 50, 75-104.

(2) Almeida, E.; Diamantino, T. C.; de Sousa, O. Marine Paints: The Particular Case of Antifouling Paints. Prog. Org. Coat. 2007, 59, 2-20.

(3) Hadjesfandiari, N.; Yu, K.; Mei, Y.; Kizhakkedathu, J. N. Polymer Brush-Based Approaches for the Development of Infection-Resistant Surfaces. J. Mater. Chem. B 2014, 2, 4968-4978.

(4) Vasilev, K.; Cook, J.; Griesser, H. J. Antibacterial Surfaces for Biomedical Devices. Expert Rev. Med. Devices 2009, 6, 553-567.

(5) Santo, C. E.; Lam, E. W.; Elowsky, C. G.; Quaranta, D.; Domaille, D. W.; Chang, C. J.; Grass, G. Bacterial Killing by Dry Metallic Copper Surfaces. Appl. Environ. Microbiol. 2011, 77, 794-802.

(6) Bellotti, N.; Romagnoli, R.; Quintero, C.; Domínguez-Wong, C.; Ruiz, F.; Deyá, C. Nanoparticles as Antifungal Additives for Indoor Water Borne Paints. Prog. Org. Coat. 2015, 86, 33-40.

(7) Murata, H.; Koepsel, R. R.; Matyjaszewski, K.; Russell, A. J. Permanent, Non-leaching Antibacterial Surfaces 2: How High Density Cationic Surfaces Kill Bacterial Cells. Biomaterials 2007, 28, 4870-4879.

(8) Ahlström, B.; Chelminska-Bertilsson, M.; Thompson, R. A.; Edebo, L. Submicellar Complexes May Initiate the Fungicidal Effects of Cationic Amphiphilic Compounds on Candida albicans. Antimicrob. Agents Chemother. 1997, 41, 544-550. 
(9) Codling, C. E.; Maillard, J. Y.; Russell, A. D. Aspects of the Antimicrobial Mechanisms of Action of a Polyquaternium and an Amidoamine. J. Antimicrob. Chemother. 2003, $51,1153-1158$.

(10) Kohnen, W.; Kolbenschlag, C.; Teske-Keiser, S.; Jansen, B. Development of a Longlasting Ventricular Catheter Impregnated with a Combination of Antibiotics. Biomaterials 2003, 24, 4865-4869.

(11) Aumsuwan, N.; Heinhorst, S.; Urban, M. W. Antibacterial Surfaces on Expanded Polytetrafluoroethylene; Penicillin Attachment. Biomacromolecules 2007, 8, 713-718.

(12) Banerjee, I.; Pangule, R. C.; Kane, R. S. Antifouling Coatings: Recent Developments in the Design of Surfaces that Prevent Fouling by Proteins, Bacteria, and Marine Organisms. Adv. Mater. 2011, 23, 690-718.

(13) Oliveira, R. D. C.; Santelli, R. E.; de Carvalho Oliveira, R.; Santelli, R. E. Occurrence and Chemical Speciation Analysis of Organotin Compounds in the Environment: A Review. Talanta 2010, 82, 9-24.

(14) Cavallaro, A.; Taheri, S.; Vasilev, K. Responsive and "Smart" Antibacterial Surfaces: Common Approaches and New Developments (Review). Biointerphases 2014, 9, 029005-1-029005-10.

(15) Genzer, J.; Efimenko, K. Recent Developments in Superhydrophobic Surfaces and their Relevance to Marine Fouling: A Review. Biofouling 2006, 22, 339-360.

(16) Scardino, A. J.; Zhang, H.; Cookson, D. J.; Lamb, R. N.; de Nys, R. The Role of Nano-Roughness in Antifouling. Biofouling 2009, 25, 757-767.

(17) Baier, R. E. Surface Behaviour of Biomaterials: The Theta Surface for Biocompatibility. J.Mater. Sci . Mater. Med. 2006, 17, 1057-1062. 
(18) Schumacher, J. F.; Aldred, N.; Callow, M. E.; Finlay, J. A.; Callow, J. A.; Clare, A. S.; Brennan, A. B. Species-Specific Engineered Antifouling Topographies: Correlations between the Settlement of Algal Zoospores and Barnacle Cyprids. Biofouling 2007, 23, $307-317$.

(19) Cao, X.; Pettitt, M. E.; Wode, F.; Arpa Sancet, M. P.; Fu, J.; Ji, J.; Callow, M. E.; Callow, J. A.; Rosenhahn, A.; Grunze, M. Interaction of Zoospores of the Green Alga Ulva with Bioinspired Micro- and Nanostructured Surfaces Prepared by Polyelectrolyte Layer-by-Layer Self-Assembly. Adv. Funct. Mater. 2010, 20, 1984-1993.

(20) Graham, M. V. M.; Mosier, A. P. A.; Kiehl, T. R. T.; Kaloyeros, A. E. A.; Cady, N. N. C. Development of Antifouling Surfaces to Reduce Bacterial Attachment. Soft Matter 2013, 9, 6235-6244.

(21) Chen, S.; Li, L.; Zhao, C.; Zheng, J. Surface Hydration: Principles and Applications toward Low-fouling/nonfouling Biomaterials. Polymer 2010, 51, 5283-5293.

(22) Lin, P.; Lin, C. W.; Mansour, R.; Gu, F. Improving Biocompatibility by Surface Modification Techniques on Implantable Bioelectronics. Biosens Bioelectron 2013, 47, 451460.

(23) Reich, L.; Stivala, S. S. Autoxidation of Poly(alkylene glycols) in Solution. J. Appl. Polym. Sci. 1969, 13, 977-988.

(24) Sakharov, A. M.; Mazaletskaya, L. I.; Skibida, I. P. Catalytic Oxidative Deformylation of Polyethylene glycols with the Participation of Molecular Oxygen. Kinet. Catal. 2001, 42, 662-668.

(25) Chen, S.; Zheng, J.; Li, L.; Jiang, S. Strong Resistance of Phosphorylcholine Selfassembled Monolayers to Protein Adsorption: Insights into Nonfouling Properties of Zwitterionic Materials. J. Am. Chem. Soc. 2005, 127, 14473-14478. 
(26) He, Y.; Hower, J.; Chen, S.; Bernards, M. T.; Chang, Y.; Jiang, S. Molecular Simulation Studies of Protein Interactions with Zwitterionic Phosphorylcholine Self-assembled Monolayers in the Presence of Water. Langmuir 2008, 24, 10358-10364.

(27) Holmlin, R. E.; Chen, X.; Chapman, R. G.; Takayama, S.; Whitesides, G. M. Zwitterionic SAMs that Resist Nonspecific Adsorption of Protein from Aqueous Buffer. Langmuir 2001, 17, 2841-2850.

(28) Kane, R. S.; Deschatelets, P.; Whitesides, G. M. Kosmotropes Form the Basis of Protein-Resistant Surfaces. Langmuir 2003, 19, 2388-2391.

(29) Chen, S.; Chen, S.; Jiang, S.; Mo, Y.; Tang, J.; Ge, Z. Synthesis and Characterization of Siloxane Sulfobetaine Antimicrobial Agents. Surf. Sci. 2011, 605, L25-L28.

(30) Fujii, K.; Matsumoto, H. N.; Koyama, Y.; Iwasaki, Y.; Ishihara, K.; Takakuda, K. Prevention of Biofilm Formation with a Coating of 2-Methacryloyloxyethyl Phosphorylcholine Polymer. J. Vet. Med. Sci. 2008, 70, 167-173.

(31) Heath, D. E.; Cooper, S. L. Design and Characterization of Sulfobetaine-containing Terpolymer Biomaterials. Acta Biomater. 2012, 8, 2899-2910.

(32) Ladd, J.; Zhang, Z.; Chen, S.; Hower, J. C.; Jiang, S. Zwitterionic Polymers Exhibiting High Resistance to Nonspecific Protein Adsorption from Human Serum and Plasma. Biomacromolecules 2008, 9, 1357-1361.

(33) Vaisocherová, H.; Zhang, Z.; Yang, W.; Cao, Z.; Cheng, G.; Taylor, A. D.; Piliarik, M.; Homola, J.; Jiang, S. Functionalizable Surface Platform with Reduced Nonspecific Protein Adsorption from Full Blood Plasma-Material Selection and Protein Immobilization Optimization. Biosens. Bioelectron. 2009, 24, 1924-1930.

(34) Bauer, S.; Finlay, J. A.; Thomé, I.; Nolte, K.; Franco, S. C.; Ralston, E.; Swain, G. E.; Clare, A. S.; Rosenhahn, A. Attachment of Algal Cells to Zwitterionic Self-Assembled 
Monolayers Comprised of Different Anionic Compounds. Langmuir 2016, 32, 56635671.

(35) Knowles, B. R.; Wagner, P.; Maclaughlin, S.; Higgins, M. J.; Molino, P. J. Silica Nanoparticles Functionalized with Zwitterionic Sulfobetaine Siloxane for Application as a Versatile Antifouling Coating System. ACS Appl. Mater. Interfaces 2017, 9, 1858418594.

(36) Jones, R. L.; Pearsall, N. C.; Batteas, J. D. Disorder in Alkylsilane Monolayers Assembled on Surfaces with Nanoscopic Curvature. J. Phys. Chem. C 2009, 113, 4507-4514.

(37) Barisik, M.; Atalay, S.; Beskok, A.; Qian, S. Size Dependent Surface Charge Properties of Silica Nanoparticles. J. Phys. Chem. C 2014, 118, 1836-1842.

(38) Hill, H. D.; Millstone, J. E.; Banholzer, M. J.; Mirkin, C. A. The Role Radius of Curvature Plays in Thiolated Oligonucleotide Loading on Gold Nanoparticles. ACS Nano 2009, 3, 418-424.

(39) Litt, M.; Matsuda, T. Siloxane Zwitterions: Synthesis and Surface Properties of Crosslinked Polymers. J. Appl. Polym. Sci. 1975, 19, 1221-1225.

(40) Estephan, Z. G.; Jaber, J. A.; Schlenoff, J. B. Zwitterion-Stabilized Silica Nanoparticles: Toward Nonstick Nano. Langmuir 2010, 26, 16884-16889.

(41) Zhuravlev, L. T. Concentration of Hydroxyl Groups on the Surface of Amorphous Silicas. Langmuir 1987, 3, 316-318.

(42) Hu, F.; Chen, K.; Xu, H.; Gu, H. Functional Short-chain Zwitterion Coated Silica Nanoparticles with Antifouling Property in Protein Solutions. Colloids Surf., B 2015, $126,251-256$.

(43) Greenwood, P.; Gevert, B. Aqueous Silane Modified Silica Sols: Theory and Preparation. Pigm. Resin Technol. 2011, 40, 275-284. 
(44) Rahman, I. A.; Vejayakumaran, P.; Sipaut, C. S.; Ismail, J.; Chee, C. K. Size-dependent Physicochemical and Optical Properties of Silica Nanoparticles. Mater. Chem. Phys. 2009, 114, 328-332.

(45) Patwardhan, S. V.; Emami, F. S.; Berry, R. J.; Jones, S. E.; Naik, R. R.; Deschaume, O.; Heinz, H.; Perry, C. C. Chemistry of Aqueous Silica Nanoparticle Surfaces and the Mechanism of Selective Peptide Adsorption. J. Am. Chem. Soc. 2012, 134, 6244-6256.

(46) Niwano, M.; Suemitsu, M.; Ishibashi, Y.; Takeda, Y.; Miyamoto, N.; Honma, K. Ultraviolet Ozone Oxidation of Si Surface Studied by Photoemission and Surface Infrared Spectroscopy. J. Vac. Sci. Technol., A 2000, 10, 3171-3175.

(47) Brinker, C. J. Hydrolysis and Condensation of Silicates: Effects on Structure. J. NonCryst. Solids 1988, 100, 31-50.

(48) Cassie, A. B. D.; Baxter, S. Wettability of Porous Surfaces. Trans. Faraday Soc. 1944, 40, 546-551.

(49) Shao, Q.; Jiang, S. Influence of Charged Groups on the Properties of Zwitterionic Moieties: A Molecular Simulation Study. J. Phys. Chem. B 2014, 118, 7630-7637.

(50) Wu, C.-J.; Huang, C.-J.; Jiang, S.; Sheng, Y.-J.; Tsao, H.-K. Superhydrophilicity and Spontaneous Spreading on Zwitterionic Surfaces: Carboxybetaine and Sulfobetaine. $R S C A d v . \mathbf{2 0 1 6}$, 6, 24827-24834.

(51) Anselme, K.; Davidson, P.; Popa, A. M.; Giazzon, M.; Liley, M.; Ploux, L. The Interaction of Cells and Bacteria with Surfaces Structured at the Nanometre Scale. Acta Biomater. 2010, 6, 3824-3846.

(52) Scardino, A. J.; Harvey, E.; De Nys, R. Testing Attachment Point Theory: Diatom Attachment on Microtextured Polyimide Biomimics. Biofouling 2006, 22, 55-60. 
(53) Scardino, A. J.; Guenther, J.; de Nys, R. Attachment Point Theory Revisited: The Fouling Response to a Microtextured Matrix. Biofouling 2008, 24, 45-53.

(54) Graham, M.; Cady, N. Nano and Microscale Topographies for the Prevention of Bacterial Surface Fouling. Coatings 2014, 4, 37-59.

(55) Vladkova, T. Surface Engineering for Non-Toxic Biofouling Control (Review). J. Univ. Chem. Technol. Met. 2007, 42, 239-256.

(56) Roach, P.; Farrar, D.; Perry, C. C. Interpretation of Protein Adsorption: Surfaceinduced Conformational Changes. J. Am. Chem. Soc. 2005, 127, 8168-8173.

(57) Linder, M. B.; Szilvay, G. R.; Nakari-Setala, T.; Penttila, M. E. Hydrophobins: The Protein-amphiphiles of Filamentous Fungi. FEMS Microbiol . Rev. 2005, 29, 877-896.

(58) Wösten, H. A. B. Hydrophobins: Multipurpose Proteins. Annu. Rev. Microbiol. 2001, $55,625-646$.

(59) Roach, P.; Farrar, D.; Perry, C. C. Surface Tailoring for Controlled Protein Adsorption: Effect of Topography at the Nanometer Scale and Chemistry. J. Am. Chem. Soc. 2006, 128, 3939-3945.

(60) Zheng, J.; Song, W.; Huang, H.; Chen, H. Protein Adsorption and Cell Adhesion on Polyurethane/Pluronic surface with Lotus Leaf-like Topography. Colloids Surf., B 2010, r7, 234-239.

(61) Puckett, S. D.; Taylor, E.; Raimondo, T.; Webster, T. J. The Relationship between the Nanostructure of Titanium Surfaces and Bacterial Attachment. Biomaterials 2010, 31, $706-713$.

(62) Linder, M. B. Hydrophobins: Proteins that Self Assemble at Interfaces. Curr. Opin. Colloid Interface Sci. 2009, 14, 356-363. 
(63) Zykwinska, A.; Pihet, M.; Radji, S.; Bouchara, J. P.; Cuenot, S. Self-assembly of Proteins into a Three-dimensional Multilayer System: Investigation of the Surface of the Human Fungal Pathogen Aspergillus fumigatus. Biochim. Biophys. Acta, Proteins Proteomics 2014, 1844, 1137-1144.

(64) Hahn, E.; Wild, P.; Hermanns, U.; Sebbel, P.; Glockshuber, R.; Häner, M.; Taschner, N.; Burkhard, P.; Aebi, U.; Müller, S. A. Exploring the 3D Molecular Architecture of Escherichia coli Type 1 Pili. J. Mol. Biol. 2002, 323, 845-857.

(65) Pratt, L. a.; Kolter, R. Genetic Analysis of Escheria coli Biofilm Formation: Roles of Flagella, Motility, Chemotaxis and Type I Pili. Mol. Microbiol. 2001, Volume: 65, $43-59$.

(66) Mitik-Dineva, N.; Wang, J.; Truong, V. K.; Stoddart, P. R.; Malherbe, F.; Crawford, R. J.; Ivanova, E. P. Differences in Colonisation of Five Marine Bacteria on Two Types of Glass Surfaces. Biofouling 2009, 25, 621-631.

(67) Rizzello, L.; Galeone, A.; Vecchio, G.; Brunetti, V.; Sabella, S.; Pompa, P. P. Molecular Response of Escherichia coli Adhering onto Nanoscale Topography. Nanoscale Res. Lett. 2012, 7,575 .

(68) Dalby, M.; Riehle, M.; Johnstone, H.; Affrossman, S.; Curtis, A. Polymer-Demixed Nanotopography: Control of Fibroblast Spreading and Proliferation. Tissue Eng. 2002, 8, 1099-1108.

(69) Tsuneda, S.; Aikawa, H.; Hayashi, H.; Yuasa, A.; Hirata, A. Extracellular Polymeric Substances Responsible for Bacterial Adhesion onto Solid Surface. FEMS Microbiol. Lett. 2003, 223, 287-292.

(70) Harding, M. W.; Marques, L. L.; Howard, R. J.; Olson, M. E. Can Filamentous Fungi Form Biofilms? Trends Microbiol. 2009, 17, 475-480. 
(71) Sterflinger, K. Fungi: Their Role in Deterioration of Cultural Heritage. Fungal Biol. Rev. 2010, 24, 47-55. 


\section{Graphical TOC Entry}

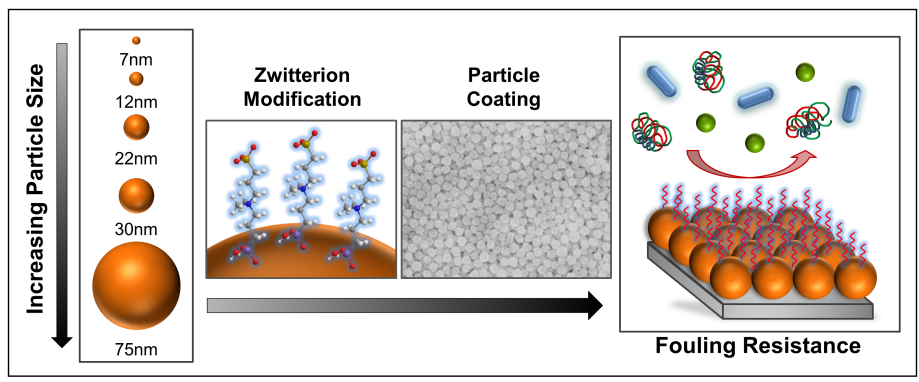




\section{Supporting Information:}

\section{Zwitterion Functionalized Silica Nanoparticle}

Coatings: The Effect of Particle Size on

\section{Protein, Bacteria, and Fungal Spore Adhesion}

Brianna R. Knowles, ${ }^{\dagger, t}$ Dan Yang, ${ }^{\dagger, \ddagger}$ Pawel Wagner, ${ }^{\ddagger}$ Shane Maclaughlin,, Michael J. Higgins, ${ }^{\dagger, \ddagger}$ and Paul J. Molino*,†,

$\dagger A R C$ Industrial Transformation Research Hub for Australian Steel Manufacturing, NSW 2522, Australia

$\ddagger$ Intelligent Polymer Research Institute, ARC Centre of Excellence for Electromaterials

Science, AIIM Facility, Innovation Campus, University of Wollongong, NSW 2500, Australia

9BlueScope Innovation Laboratories, Old Port Road, Port Kembla, NSW 2505, Australia

E-mail: pmolino@uow.edu.au 


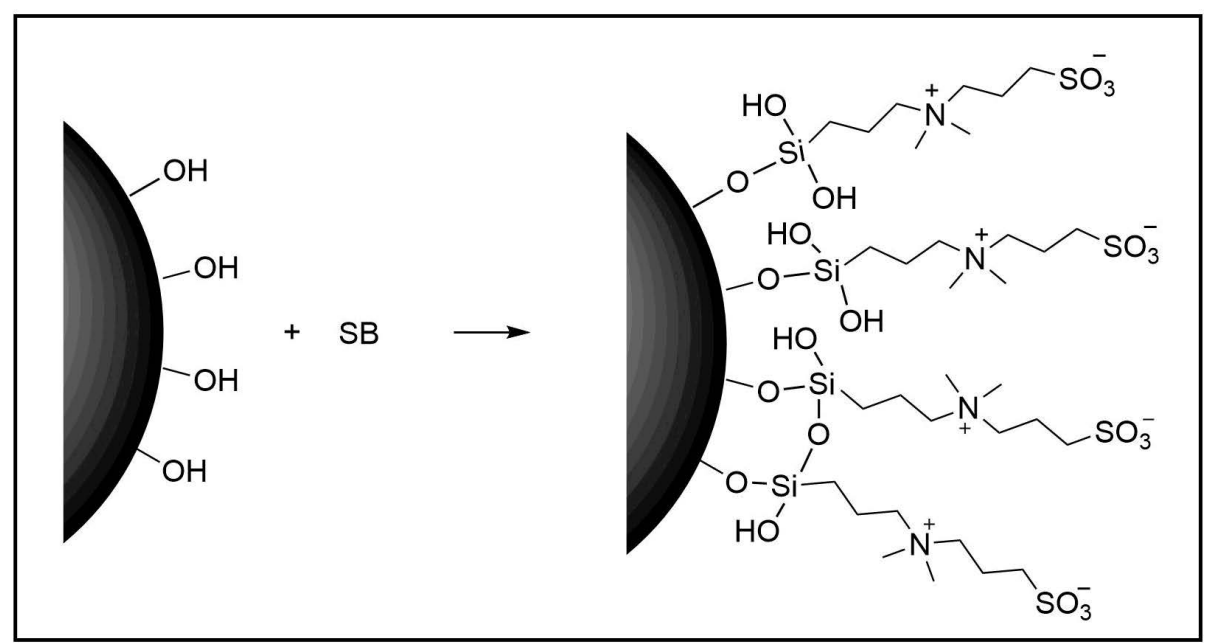

Figure S1: Schematic of SiNP functionalization with zwitterionic SB.

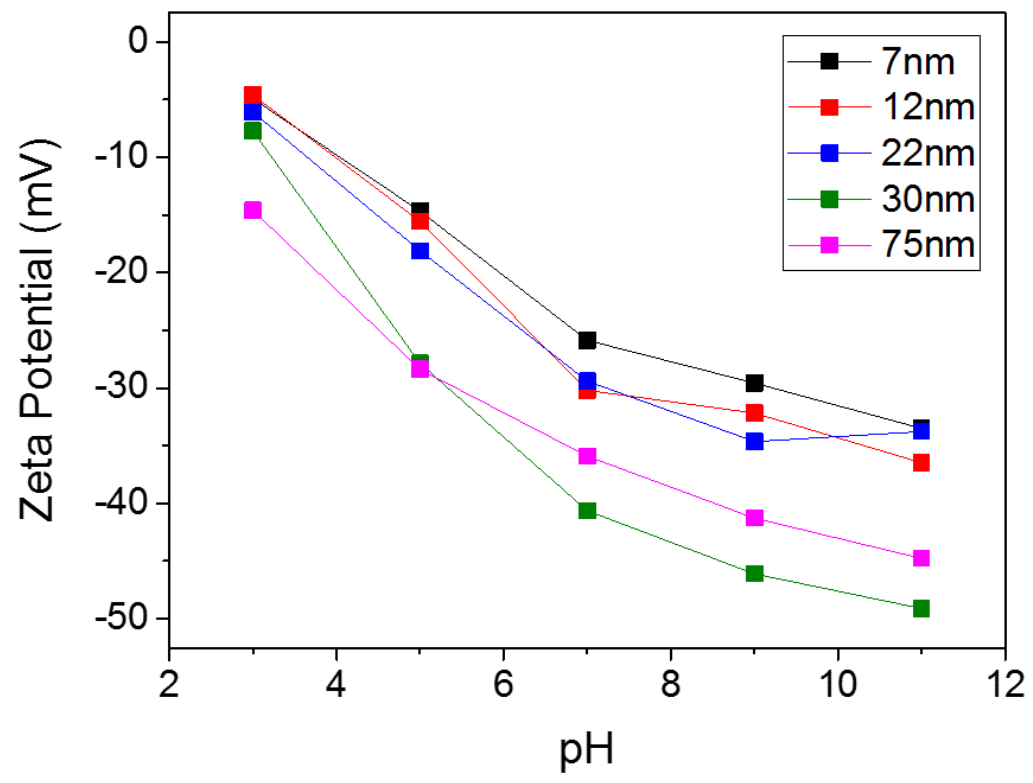

Figure S2: Zeta potential measurements performed on SiNP dispersions between $\mathrm{pH} 3.0$ and 11.0 . 


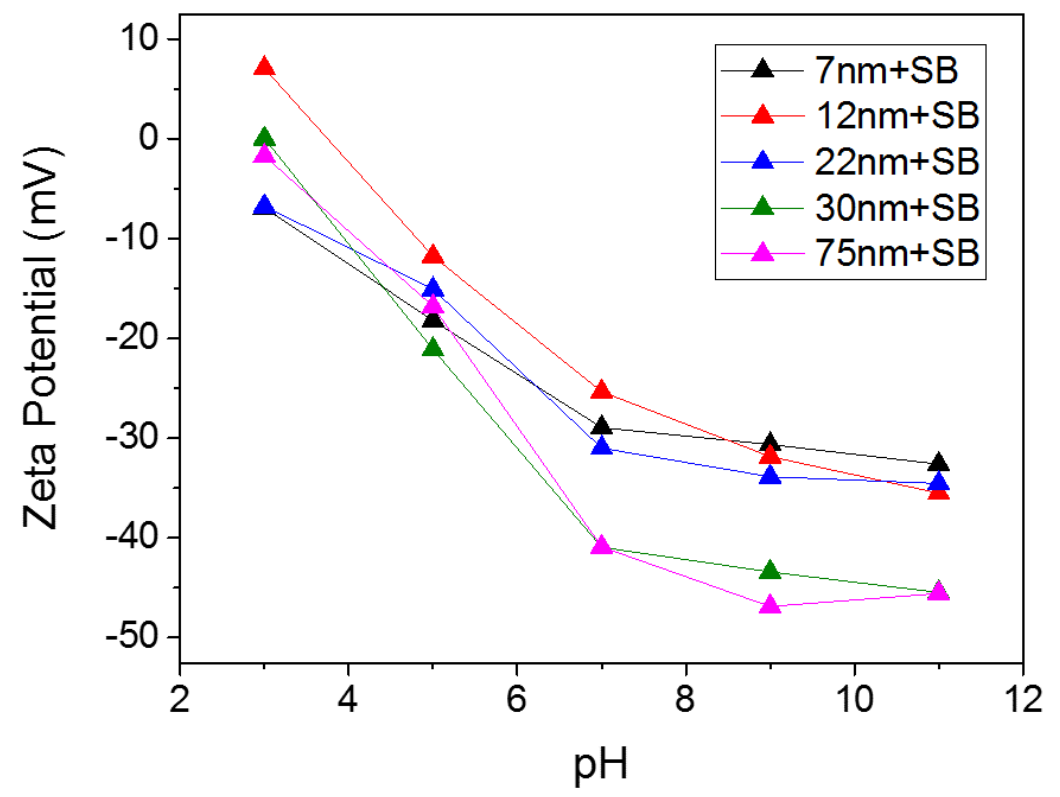

Figure S3: Zeta potential measurements performed on $\mathrm{SiNP}+\mathrm{SB}$ dispersions between $\mathrm{pH} 3.0$ and 11.0.

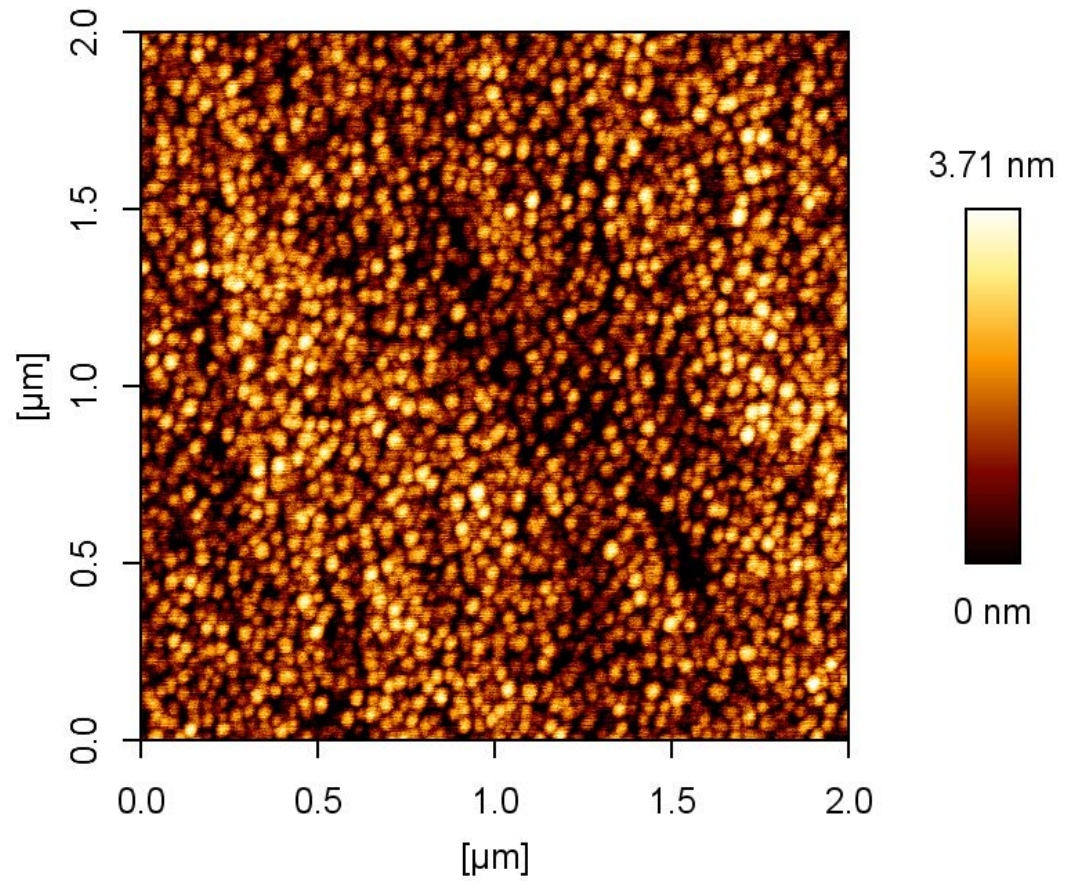

Figure S4: Example AFM scan $(2 \mu \mathrm{m} \times 2 \mu \mathrm{m})$ of a $\mathrm{SiO}_{2}$ QCM sensor. 